\title{
Situation analysis of health facilities with special reference to family planning services in Pakistan
}

Arshad Mahmood

Population Council

Muhammad Jamil Arshad

Maqsood Sadiq

Population Council

Follow this and additional works at: https://knowledgecommons.popcouncil.org/departments_sbsr-rh

Part of the International Public Health Commons, Maternal and Child Health Commons, Obstetrics and Gynecology Commons, Social and Behavioral Sciences Commons, and the Women's Health Commons How does access to this work benefit you? Let us know!

\section{Recommended Citation}

Mahmood, Arshad, Muhammad Jamil Arshad, and Maqsood Sadiq. 2012. "Situation analysis of health facilities with special reference to family planning services in Pakistan." Islamabad: Population Council. 
Situation Analysis of Health Facilities with Special Reference to Family Planning Services in Pakistan

\section{Authors:}

Arshad Mahmood Ph.D.

Muhammad Jamil Arshad

Maqsood Sadiq 



\section{Situation Analysis of Health Facilities with Special Reference to Family Planning Services in Pakistan}

Authors:

Arshad Mahmood

Muhammad Jamil Arshad

Maqsood Sadiq
Research Team:

Ashfa Hashmi

Tahira Perveen

Shagufta Faiz

Lubna Mahmood

Bushra Bano

Farzana Arif 


\section{(1) Population Council}

The Population Council, an international, non-profit, non-governmental organization established in 1952, seeks to improve the well-being and reproductive health of current and future generations around the world and to help achieve a humane, equitable, and sustainable balance between people and resources.

The Council analyzes population issues and trends; conducts research in the reproductive sciences; develops new contraceptives; works with public and private agencies to improve the quality and outreach of family planning and reproductive health services; helps governments design and implement effective population policies; communicates the results of research in the population field to diverse audiences; and helps strengthen professional resources in developing countries through collaborative research and programs, technical exchange, awards, and fellowships.

The Population Council reserves all rights of ownership of this document. No part of this publication may be reproduced, stored or transmitted in any form by any means-electronic, photocopying, recording or otherwise-without the permission of the Population Council.

For inquiries, please contact:

Population Council

Add: $\quad$ 7, Street 62, F-6/3, Islamabad, Pakistan

Tel: $\quad 92518445566$

Fax: $\quad 92512821401$

Email: info.pakistan@popcouncil.org

Web: http://www.popcouncil.org http://www.falah.org.pk

Layout and Design: Ali Ammad

Published: March, 2012

Disclaimer

"This study/report is made possible by the generous support of the American people through the United States Agency for International Development (USAID). The contents are the responsibility of the Population Council, Islamabad and do not necessarily reflect the views of USAID or the United States Government." 


\section{Table of Contents}

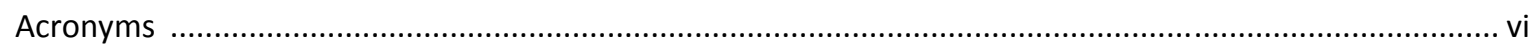

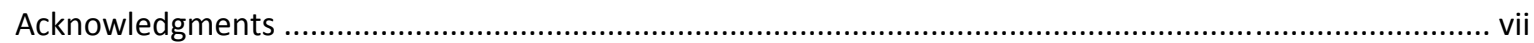

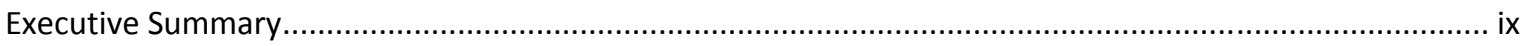

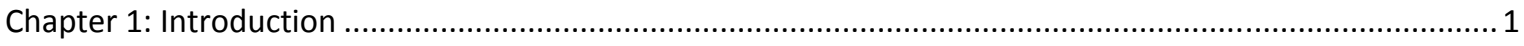

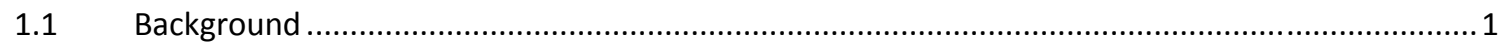

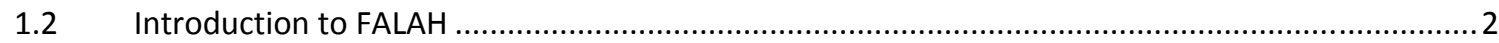

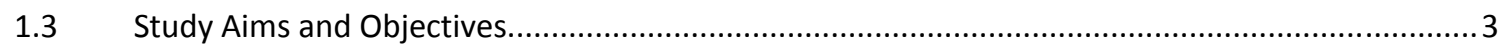

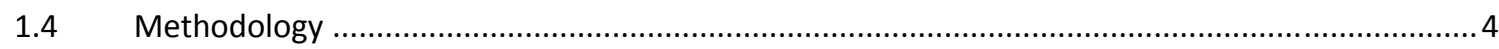

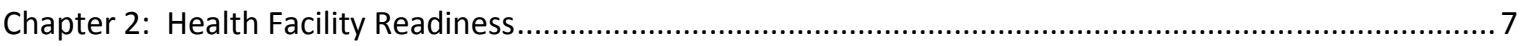

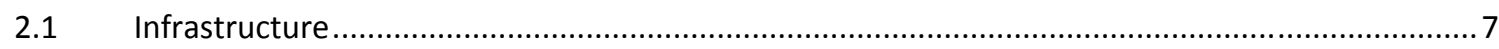

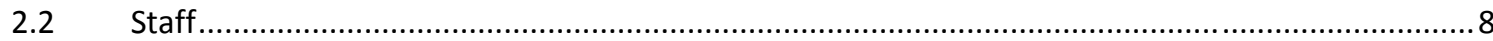

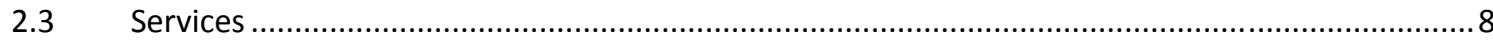

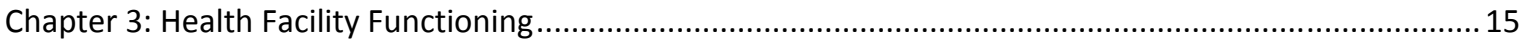

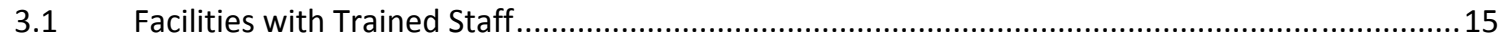

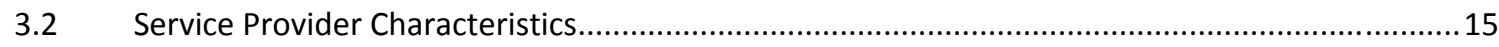

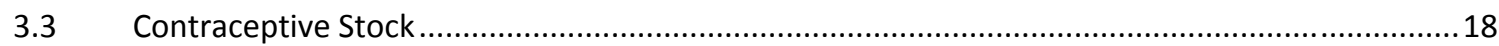

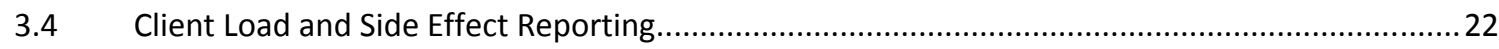

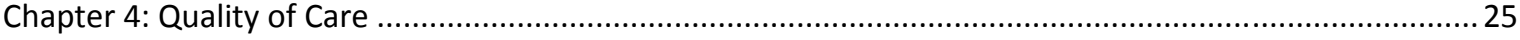

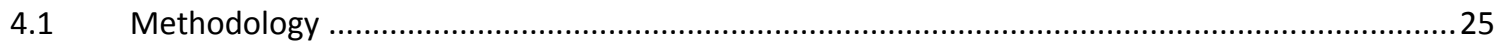

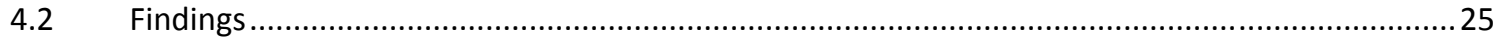

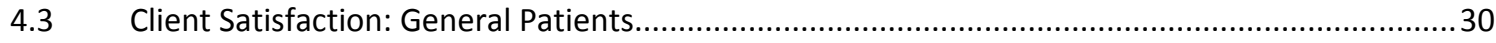

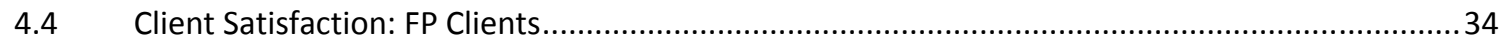

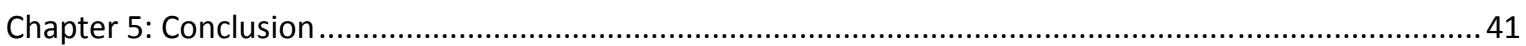

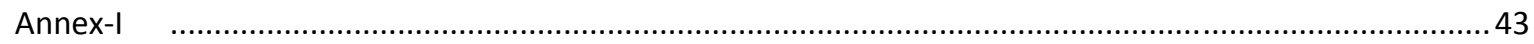

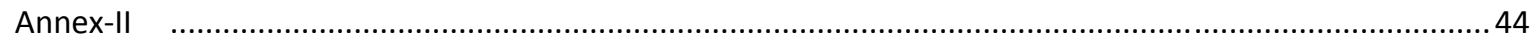

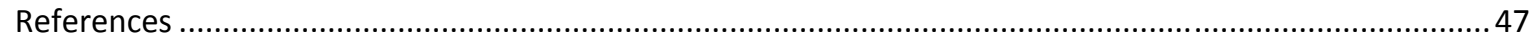




\section{List of Tables}

Table 1.1: Number of facilities covered in the survey by the type of interview/observations.

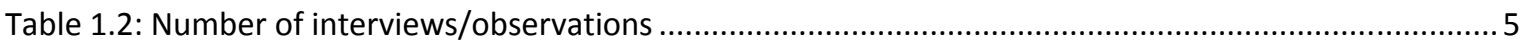

Table 2.1: Percentage of health facilities possessing basic infrastructure ...............................................

Table 2.2: Number and percent of health facilities by the type of services available for birth spacing........... 9

Table 2.3: Percentage of facilities with at least one staff member trained, by type of training and staff ..... 10

Table 2.4: Percentage of facilities with availability of IEC material by training status* ............................... 11

Table 2.5: Number and percent of facilities, by type and protocol of storage of contraceptives .................. 12

Table 3.1: Percentage of providers by knowledge of FP/birth spacing, according to training status............. 16

Table 3.2: Counseling topic and comprehensible information, by training of provider ............................... 17

Table 3.3: Usual contraceptive stock, by type of contraceptive and availability, and provider training status.

Table 3.3A: Type of action on stock outs and reporting result, by provider training status ..........................20

Table 3.4: Method of submission of monthly contraceptive demand, by provider training status ...............20

Table 3.5: Percentage of facilities, by contraceptive supply, compared to demand, according to training... 21

Table 3.6: Contraceptive stocks and maintenance status of FP registers, by provider training status ..........21

Table 3.7: Client load and duration since last FP client, by provider training status ......................................2 23

Table 3.8: Average number of clients per provider who reported receiving clients for side effects, by

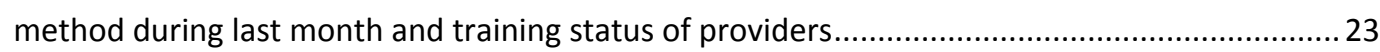

Table 3.9: Percentage of providers who received complications for side effects, by type of side effects according to provider training

Table 4.1: Percentage of client/patient health decision-making and advice.......

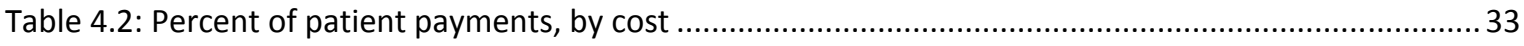

Table 4.3: Percentage of client assessments, by type and provider training ............................................ 35

Table 4.4: Percentage of clients provided FP information, by type of information and provider training......37

Table 4.5: Percentage of satisfied clients 38 


\section{List of Figures}

Figure 2.1: Percentage of staff present on day of visit

Figure 2.2: Average number of FP clients per facility, for last six months, by training status of facilities...... 13

Figure 3.1: Percentage of facilities whose staff received training, by type of training received * 15

Figure 3.2: Percentage of facilities with contraceptive availability on the day of visit, by training status ..... 18

Figure 3.3: Average FP client load per facility during last month $(\mathrm{N}=115)$ 22

Figure 4.1: Impact of SAHR training component 'Salutation' on provider behavior and interaction with clients by their training status

Figure 4.2: Impact of SAHR training component 'Assessment' on provider behavior and interaction with clients, by provider training status

Figure 4.3: Impact of SAHR training component 'Help' on provider behavior and interaction with clients, by training status

Figure 4.4: Impact of SAHR training component 'Reassurance' on provider behavior and interaction with clients by their training status

Figure 4.5: Percentage of clients/patients, by type of facility consulted for usual treatment 30

Figure 4.6: Percentage of clients/patients accompanied to health facility 31

Figure 4.7: Percentage of clients/patients, by time taken to reach health facilities

Figure 4.8: Percentage of client/patient means of travel to health facility......

Figure 4.9: Percentage of clients/patients by opinion about service affordability

Figure 4.10: Percentage of clients by the objective of visit to facilities for family planning according to the training status of providers.

Figure 4.11: Percentage of clients informed about examination, by training of providers 35

Figure 4.12: Percent contraception use at exit interview 36

Figure 4.13: Help for clients, by percent of clients of trained and untrained providers..... 36

Figure 4.14: Percentage of clients reporting availability of method by the status of training of the provider 37

Figure 4.15: Percentage of clients instructed on follow up visits, by provider training status 38 


\section{Acronyms}

BHU Basic Health Unit

BP Blood Pressure

CCA Client Centered Approach

CCFPS Client Centered Family Planning Services

CPR Contraceptive Prevalence Rate

DG Director General

DHIS District Health Information System

DHQ District Headquarter

CLR Contraceptive Logistics Report

$\mathrm{DOH}$ Department of Health

DSM District Support Manager

DTC District Technical Committee

EDO Executive District Officer

FALAH Family Advancement for Life and Health

FP Family Planning

FWC Family Welfare Centre

HMIS Health Management Information System

ICPD International Conference on Population and Development

IEC Information, Education and Communication

IUD Intra Uterine Device

IUCD Intra Uterine Contraceptive Device

LHV Lady Health Visitor

LHW Lady Health Worker

$\mathrm{MCH} \quad$ Mother and Child Health

MDGs Millennium Development Goals

PC Population Council

PHC Primary Health Care

PPHI People's Primary Healthcare Initiative

$\mathrm{RH} \quad$ Reproductive Health

RHC Rural Health Centre

SAHR Salutation, Assessment, Help and Reassurance

STD Sexually Transmitted Disease

THQ Tehsil Headquarter

USAID United States Agency for International Development 


\section{Acknowledgments}

FALAH, a USAID funded five year project, was launched in 2007 which was implemented by a consortium including Population Council as a lead partner along with other organizations: Greenstar, HANDS, Jhpiego, Mercy Corps, RSPN and Save the Children, US. FALAH aimed to improve the health of women and children leading to overall health and prosperity of family through repositioning of family planning with the promotion of the idea of birth spacing. One of the objectives of the project was to enhance demand for and quality of birth spacing services in public sector specifically at health facilities being the large network for delivery of services. With this objective FALAH also aimed to ensure contraceptives availability with concerted efforts in collaboration with Government functionaries. For strengthening of contraceptives flow, training on contraceptives logistics management was imparted to health staff and thereafter sensitization of the health authorities and others concerned was realized highlighting non-availability of contraceptives as one of the reasons for lower contraceptive use.

To measure the impact of above mentioned activities, this study was conducted in project districts. Population Council's professional staff was engaged for this study. Training of the staff for the field work was accomplished by the team of public health specialists. We would like to thank Dr. Zakir Hussain and Dr. Muhammad Saleem for their contribution in training the field teams on the SAHR components. We would like to particularly acknowledge the hard work of Ms. Shagufta Naheed, Ms. Tahira Perveen, Ms. Lubna Mahmood, Ms. Ashfa Hashmi, Ms. Bushra Bano, Ms. Farzana Arif and Ms. Zubaida Khanum for quality data collection. They worked not only themselves diligently but supervised the field team in the field. We should also pay thanks to Mr. Ali Ammad who gave layout to this report.

Our special thanks to Dr. Ian Askew, Director Reproductive Health, Population Council for reviewing the report and to Mr. Robert Pursley for editing the final report. Finally, Dr. Zeba Sathar, Country Director Population Council Islamabad provided invaluable input and was instrumental in the quality of the report produced. In the last, we are thankful to Dr. Ali Mohammad Mir and Dr. Gul Rashida for their comments and suggestions in analyzing the provider-client interaction aspects of the data. 



\section{Executive Summary}

Despite Pakistan's long history of family planning (FP) efforts, dating to the 1950s, desired success has yet to be achieved, due to information, education and communication (IEC) strategy weaknesses, leading to misconceptions by the public that FP means limiting children; as well as focus on women with no, or less, attention on men; and FP programs' isolation from the 'mainstream' health system. The FALAH project, launched in 2007, funded by USAID, and implemented by a consortium of partners led by The Population Council, sought to shift FP perception to birth spacing from child limiting, as well as actively attempting to engage men, and building provider capacity.

This report details the findings of an assessment of FALAH's FP and birth spacing impact. The study assessed public health facility readiness for offering FP and birth spacing services by interviewing in-charges and providers, as well as assessing the types of services provided and service providers' characteristics. The study also examined the facilities' quality of care through observing client and provider interactions, while client satisfaction was assessed in exit interviews. The main findings are summarized below:

\section{a) Health Facility Readiness}

Virtually all health facilities had electricity, but few (39\%) had provisions for ensuring continued power during periodic outages. Female medical staff delivering FP/birth spacing services, among others, were posted at 87 percent of facilities, and on the day of the visit, 79 percent of these were available; overall staff presence on the day of visit was at 84 percent. Sixty-nine percent of facilities' male staff were trained according to Client Centered Family Planning Services (CCFPS)Basic, while 70 percent of facilities' female staff were trained in CCFPS-Advance, and 51 percent of facilities' female staff were trained in IUCD skills.

The vast majority (91\%) of facilities are delivering birth spacing services, but 30 percent did not have a separate client examination room. Similarly, 94 percent of facilities offered birth spacing counseling, but just under half (47\%) had no separate room. An IUCD kit was available in 62 percent of facilities, and 60 percent of facilities provided male clients with birth spacing counseling. While 90 percent of facilities with trained staff displayed IEC materials, only 57 percent of facilities with untrained staff did.

Trained providers more clearly understood the concepts of birth spacing and FP compared to untrained providers. For example, 78 percent of trained, compared with 50 percent of untrained, providers thought FP means "plan your family according to your resources"; conversely, 26 
percent of untrained providers and eight percent of trained providers defined FP as limiting children.

During counseling sessions, the majority of trained providers (77\%) addressed FP, while 64 percent of trained providers addressed birth spacing. Two-thirds of facilities reported contraceptive availability at the time of visit, with little difference according to whether a trained provider was present. More facilities (76\%) with trained providers were proactively requisitioning contraceptive supplies compared to facilities (64\%) in which no provider was trained.

The average number of FP clients seen monthly in each facility was 29; two-thirds of these were new, and one-third was for follow-up or return visits. While 84 percent of providers had worked with a client within the past 10 days, 16 percent worked with their last client more than 10 days previously.

\section{b) Quality of Care}

The largest proportion of clients (44\%) sought treatment from Basic Health Units (BHUs), while 34 percent went to Rural Health Centers (RHCs). Observations of provider-client interactions revealed that trained providers performed much better than untrained providers. Just over half of interviewed clients/patients traveled to health facilities on foot, incurring no transportation cost. Moreover, 92 percent of clients reported that services were affordable.

Among FP clients, the majority either started or re-supplied a method, followed by attending facilities for side effect issues. Women attended by trained (46\%) providers were more likely to report questions asked of them, as well as examination, than women attended by an untrained (39\%) provider; examinees of trained providers were more likely to be informed of the reasons for their exam (73\% versus $60 \%$ ), to report that their needed methods or medicines were available in the same place (81\% versus $73 \%$ ), and provided with follow-up instructions ( $89 \%$ versus $77 \%$ ). Overall levels of satisfaction were high, at 93 percent; 98 percent said they would recommend that others attend the same facility.

In conclusion, the study's overall findings confirm FALAH had a positive impact on FP and birth spacing services in its target districts. FALAH can be considered a successful model, and one that should be replicated elsewhere. 


\section{Chapter 1: Introduction}

\subsection{Background}

Family planning (FP) services in Pakistan started in the 1950s in the private sector, and thereafter in the public sector. The country's FP program has not been able, however, to achieve its desired success. Pakistan's population has more than quadrupled since 1950, reaching 177 million in 2011 (Finance Division 2011). Recent fertility estimates are available from two main sources: PDHS 2006-07, which estimates a TFR of 4.1 (NIPS and Macro International Inc. 2008), and the Pakistan Demographic Survey (PDS), which estimates TFR at 3.7 in 2007 (Federal Bureau of Statistics 2007). Overall, Pakistan's reproductive health $(\mathrm{RH})$ indicators are poor. According to the Pakistan Demographic and Health Survey 2006-07, the maternal mortality rate in Pakistan was 276 per 100,000 live births. Infant mortality declined from 96 deaths per 1,000 live births in 1990 to 78 deaths per 1,000 live births in 2005, while neonatal mortality remained at 54 per 1,000 live births from 1990 to 2006 (NIPS and Macro International Inc. 2008). These indicators are worse for women in poor households (Sathar et al. 2004).

Only 30 percent of currently married women use any contraceptive. Among contraceptive users, the most common method is female sterilization (8.2\%) followed by condom use (6.8\%). Traditional methods of withdrawal and rhythm were also quite popular: 7.9 percent of women reported using them (NIPS and Macro International Inc. 2008). Less than half (48\%) of modern method users rely on the public health sector for services, while 30 percent use the private sector, and 12 percent use the commercial sector. In the public sector, the most important FP service sources are government hospitals and RH service centers (RHSC; 32\% of users), with only 1.6 percent through RHCs and MCH centers (NIPS and Macro International Inc. 2008).

The public health sector includes District Headquarter Hospitals (DHQs), Tehsil Headquarter Hospitals (THQs), Rural Health Centers (RHCs), and Basic Health Units (BHUs). Currently, in rural areas, at BHUs and RHCs medical officers/medical technicians, dispensers and lady health visitors (LHVs) provide a range of Primary Health Care (PHC) services. Although FP services are a part of the general preventive health care package, they are limited in the public health sector. FP services in the general preventive health package include information on birth spacing benefits, provision of condoms, pills, injectables, and IUCD insertion. It is imperative FP becomes a priority for PHC and RH programs to reduce Pakistan's maternal and child mortality. The health sector should deliver FP information and services as part of its PHC package, not just as an implicit additional service. To make a real difference and make FP an intrinsic part of the health system, prioritizing it at all service delivery levels is necessary. To make it happen, FALAH trained health care providers in public sector facilities in project districts on client-centered FP services. 
Quality of care is now a central concern in the international FP and RH care community (RamaRao and Mohanam 2003), and Situation Analysis is a popular measurement approach that helps policymakers and managers set plans. Situation Analysis is comprehensive and standardized, systematically assessing both FP and RH program service delivery readiness, as well as client quality of care (Miller et al. 1998).

A health facility assessment evaluated the health system's strengths and weaknesses. Health facility assessments generate information on indicators of service readiness and quality. Health facility assessment data are useful as independent analyses of system strengths and weaknesses, and aid health managers in their decision-making processes. Health facility readiness is measured either by a one-item indicator (a counseling room or consultation table, for example) or with a multi-item measure (Fapohunda 2012). This assessment has utilized a multi-item measure, for most accurately assessing functioning facilities and help making them as fully operational as possible.

\subsection{Introduction to FALAH}

Family Advancement for Life and Health (FALAH) was a USAID-funded project, implemented 2007 to 2012 by a consortium of partners led by Population Council. The project promoted birth spacing and increased contraceptive use, as well as addressing barriers contributing to Pakistan's slow pace of fertility decline, including:

1. FP misconceptions among the general public;

2. FP activity focusing on women with less, or no, focus on men;

3. FP program isolation from the Health Department.

FALAH repositioned FP in Pakistan by promoting the concept of birth spacing, with special emphasis on mother and child health leading to families' overall health and prosperity. This strategy increased FP service demand (Mahmood 2012). In addition, the project also focused on men by organizing special activities, such as group meetings with men and involving religious Ulama in promoting birth spacing for health benefits (Population Council 2009).

FALAH made efforts to improve FP and birth spacing service quality by training health personnel, specifically utilizing Client-Centered Family Planning Services (CCFPS)-Basic, CCFPS-Advance, and IUCD insertion skills. CCFPS-Basic was provided to male Health Department providers, notably doctors, health technicians, and dispensers. CCFPS-Advance targeted female providers, with indepth knowledge of contraceptive technology and side effect management. IUCD training, in proper insertion and removal skills, was provided to those trained on CCFPS-Advance. Both the Basic and Advance trainings also include a counseling component. 
"The logistic system is a vital part of any program, including family planning, which provides services. A logistic system provides excellent client service by fulfilling the six rights: ensuring that the right goods, in the right quantities, in the right condition, are delivered to the right place, at the right time, for the right cost" (Ministry of Population Welfare 2007). FALAH addressed contraceptive supply through its contraceptive logistics management training for district and facility personnel. As a follow-up, for strengthening facility contraceptive supply, during the project a series of visits in FALAH districts quantified contraceptive availability and identified its related problems. Efforts were made to resolve supply issues on the spot or, if necessary, higher management of the Health and Population Welfare departments as well as the People's Primary Health Care Initiative (PPHI) was involved. Visits were made to EDOs (Health), District Support Managers (PPHI), LHW Program Coordinators, District Population Welfare Officers and other related officers and staff, especially at facilities.

During field visits contraceptives were found, overall, generally available from District Population Welfare Offices and LHWs, however Department of Health (DoH)/PPHI clinics were not as well supplied, and contraceptive availability was a big issue at DoH clinics. Therefore, the study focused on improving supply at the DoH/PPHI and its facilities, identifying issues and problems and attempting to solve them immediately, at all levels.

The project originally focused on 20 districts, with some swapped due to security concerns, and a 2009 expansion led to coverage planned in 26 districts. Ultimately, after curtailment by USAID, full implementation occurred in 15 of the 26 districts. This report evaluates health facilities in 14 districts in which both baseline and endline household surveys were also conducted:

Khyber Pakhtunkhwa: Charsadda, Mardan, Swabi, and Mansehra;

Punjab: Bahawalpur, Dera Ghazi Khan, Jhelum, and Rajanpur;

Sindh: Dadu, Ghotki, Larkana, Sanghar, Sukkur, and Thatta.

\subsection{Study Aims and Objectives}

FALAH has made extensive efforts to generate demand for birth spacing services, improve quality of service provision, and strengthen contraceptive supply systems for facilities. The overall aim of this study is to assess both health facility readiness for providing clients birth spacing services, as well as quality of services. Specifically, the study assesses:

1. Facility promotion of $\mathrm{FP} /$ birth spacing;

2. Availability of quality birth spacing services;

3. Availability of a range of contraceptive methods;

4. Service provider FP knowledge; 
5. Attitudes and behavior of trained (on SAHR) and untrained service providers towards FP clients;

6. FP client satisfaction.

\subsection{Methodology}

Situation Analysis methodology was developed by Population Council for assessing FP program functions at the 'grass root' level. In this methodology, data are collected on availability, function, and services, as well as quality. Information is collected on key indicators of FP services, quality of care, and performance of service outlets. The standard instruments for all situation analyses include an inventory for facilities and services, an observation guide for client-provider interactions, an exit questionnaire for FP clients at service outlets, and a guide for provider interviews (Mensch et al. 1994).

Situation Analysis assesses facility readiness for FP services as well as quality of service. Readiness encompasses infrastructure, contraceptive supply and logistics, building repair, management information systems, and staff availability. Quality addresses interactions between client and provider (RamaRao and Mohanam 2003). This Situation Analysis is comprised of these elements.

The study was conducted in a sample of 11 health facilities (5 BHUs, 4 RHCs, 1 THQ hospital and 1 DHQ hospital) in 14 FALAH districts in three provinces, with facilities in each district chosen randomly. Four research tools collected information on multiple items, assessing facility infrastructure and readiness, provider-client interaction, and data on quality of care indicators (Miller et al. 1997):

1. Questionnaire for health facility in-charges;

2. Service provider questionnaire (Female Medical Officer, Female Medical Technician, LHV);

3. Guide for observing provider-client interactions; and

4. Facility-based client exit interviews.

Staff training was conducted December 1-3, 2011, with 10 participants at Population Council's Islamabad office. After the training, field staff was divided into five teams, each with a Population Council staff member and one experienced, CCA-trained LHV hired for the task. One team member interviewed facility in-charges and service providers, while the other observed clientprovider interaction and interviewed those clients at their exit. Client and provider interactions were observed without making providers aware their observation. A maximum of three clients for each provider were observed and interviewed, depending client availability, but provider interviews were not limited. Data collection took place from December 2011 to January 2012. 
Table 1.1 shows the number and type of facilities covered, and Table 1.2 reflects the number of observations and in-charges, providers interviewed as well as exit interviews for this study.

Table 1.1: Number of facilities covered in the survey by the type of interview/observations

\begin{tabular}{l|c|c|c|c|c} 
Module & DHQ Hospital & THQ Hospital & RHC & BHU & Total \\
\hline In-charge interviewed & 10 & 12 & 44 & 75 & 141 \\
\hline Providers interviewed & 9 & 12 & 42 & 73 & 136 \\
\hline Observations & 8 & 11 & 40 & 66 & 125 \\
\hline Exit Interview of clients/patients & 8 & 11 & 42 & 65 & 126 \\
\hline
\end{tabular}

Table 1.2: Number of interviews/observations

\begin{tabular}{l|c} 
Module & Total \\
Interviews of In-charge of health facility & 141 \\
\hline Provider interviews & 175 \\
\hline Observations & 432 \\
\hline Facility-based exit interviews & 432 \\
\hline
\end{tabular}





\section{Chapter 2: Health Facility Readiness}

Chapters 2 and 3 discuss health facility readiness for FP and birth spacing services; readiness refers to infrastructure, contraceptive supply and logistics, building conditions, management information systems, and trained staff availability (RamaRao and Mohanam 2003), all of which help determine health facility utilization by clients and patients. This chapter details findings from interviews with in-charges, discussing infrastructure, assigned staff present during visits, services and related available necessities, trained staff, IEC activities, storage, and facility performance with FP/birth spacing clientele.

\subsection{Infrastructure}

Infrastructure, along with amenities, affects facility readiness and performance. Key indicators have been picked for seeing infrastructure/buildings of the facilities. Uninterrupted electric supply is imperative to make the facility fully functional especially in emergency case. Sometimes patients/clients have to wait for a long for consultations/examinations. So waiting area protected from sun and rain and toilets for female patients are necessity. Cleanliness is much more important as well to avoid infections. The existence of all such amenities and cleanliness was observed /judged by the visited survey team. As seen in Table 2.1, almost all the facilities visited were electrified. It is encouraging if compared with Kenya where only 47 percent of the health facilities surveyed had electricity (Fapohunda 2012). However, given the current situation with frequent power load shedding - particularly in rural areas - it is noteworthy that 61 percent of facilities had no substitute arrangement of a generator or UPS. This may have implications for the care of patients. Other indicators, however, were satisfactory: 83 percent had separate toilets for females; 95 percent had a waiting area, and so on.

Table 2.1: Percentage of health facilities possessing basic infrastructure

\begin{tabular}{l|r|r} 
Facilities having: & Facilities & Percent \\
Electrification & 141 & 98.6 \\
\hline Generator or UPS & 140 & 38.6 \\
\hline A separate toilet for female clients/patients & 140 & 82.9 \\
\hline Waiting area arrangements for clients/patients & 141 & 95.0 \\
\hline Sitting area protected from sun and rain & 139 & 96.4 \\
\hline Cleanliness & 140 & 85.0 \\
\hline
\end{tabular}




\subsection{Staff}

Staff absence at a facility can undermine public confidence and, thus, utilization of its services. This is particularly important with FP, because failure to receive service can result in unwanted pregnancy. This survey found that 84 percent of assigned staff was on duty during its visits, an encouraging percentage, if compared with a previous study in 170 health facilities in 19 randomly selected districts in Punjab and Khyber Pakhtunkhwa (then NWFP): In Punjab, only 42.5 percent, and in NWFP 72 percent, of required staff was present (Ali et al. 2008).

Figure 2.1: Percentage of staff present on day of visit

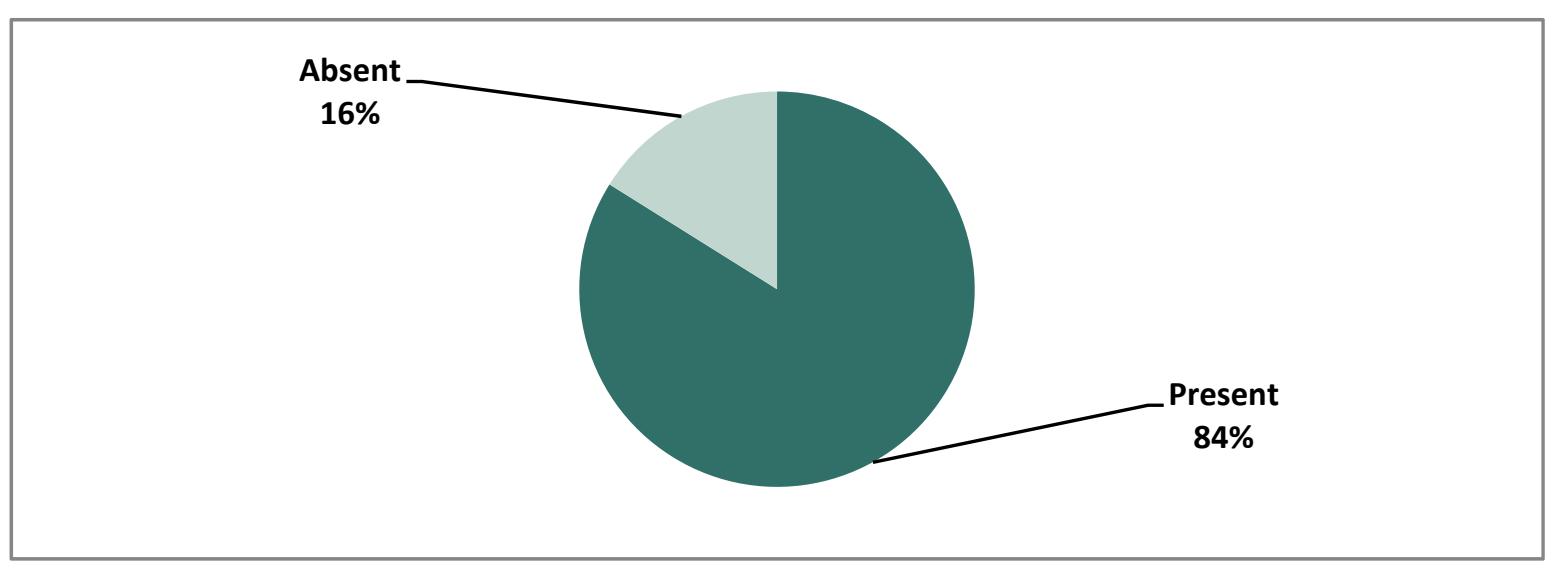

\subsection{Services}

Consistent with a holistic, integrated FP approach, services should be offered in 'mainstream' health facilities. Indeed, FP/birth spacing services are mandatory in Pakistan's public sector health facilities. This survey examined the extent to which this commitment is fulfilled.

\section{a) Birth Spacing Services}

Table 2.2 shows that 91 percent of facilities in 14 FALAH districts in this survey provided birth spacing services; an earlier assessment of public health facilities in Kohat district indicated 86 percent of assessed facilities were offering FP services (WHO 2010). In this survey, only 70 percent of facilities had a separate examination room, IUCD kits were available in 62 percent of facilities, and female medical staff delivering $\mathrm{FP} /$ birth spacing services, among others, was posted at 87 percent of visited facilities in these 14 districts. Female staff presence on the day of visit was 79 percent. In the absence of female staff at a facility, female clients are reluctant to seek FP services from male personnel, especially in rural communities, as observed in an earlier study (Bruce 1990). It was also observed that 60 percent of facilities visited had male FP clients, reflecting male FP involvement. Male involvement could partially be attributed to FALAH, which has made efforts 
to motivate male participation by holding husband group meetings providing information on birth spacing benefits for mother and child health. Moreover, it is encouraging that 94 percent of facilities offer counseling, but only 53 percent had a separate room for this purpose.

Table 2.2: Number and percent of health facilities by the type of services available for birth spacing

\begin{tabular}{|c|c|c|}
\hline Services & Facilities & Percent \\
\hline 1. Birth spacing services & 141 & 90.8 \\
\hline i. Separate room for examination of clients & 140 & 70.0 \\
\hline ii. Necessary equipments/apparatus for examination* & 140 & 98.6 \\
\hline a. Examination table & & 97.8 \\
\hline b. IUCD kit & & 61.6 \\
\hline c. Equipment for sterilization of instruments & & 74.6 \\
\hline d. Blood pressure cuffs & & 98.6 \\
\hline e. Syringes & & 99.3 \\
\hline f. Antiseptic lotion & & 85.5 \\
\hline g. Any other & & 15.2 \\
\hline iii. Female medic and paramedic posted & 139 & 87.0 \\
\hline iv. Female staff present on the day of visit & 138 & 79.0 \\
\hline v. Facilities receiving male clients for birth spacing & 141 & 59.6 \\
\hline 2. Staff dealing with male clients for birth spacing services:* & 82 & \\
\hline a. Male Medical Doctor & & 67.1 \\
\hline b. Male Health Technician & & 37.8 \\
\hline c. Dispenser & & 18.3 \\
\hline d. Any other & & 7.3 \\
\hline 3. Counseling services for birth spacing & 141 & 94.3 \\
\hline i. Separate room for counseling services & 132 & 53.0 \\
\hline
\end{tabular}

*Multiple response variable

\section{b) Staff Training}

One of FALAH's objectives was strengthening public health facility capacity by training providers on CCFPS-Basic and Advance, as well as on IUCD skills. These trainings utilized the SAHR approach (Sathar et al. 2005), along with other technical aspects. The details of SAHR components are given at Annex-I. This survey's findings show that 87 percent of visited facilities had at least one staff member with at least one FALAH training. At 69 percent of facilities, male staff was trained on CCFPS-Basic (Table 2.3). At 35 percent of facilities, a male doctor was trained in CCFPS-Basic, 
followed by 25 percent of facilities with a trained dispenser, 23 percent with a male health technician, and 10 percent with other male staff trained in CCFPS-Basic.

Table 2.3: Percentage of facilities with at least one staff member trained, by type of training and staff

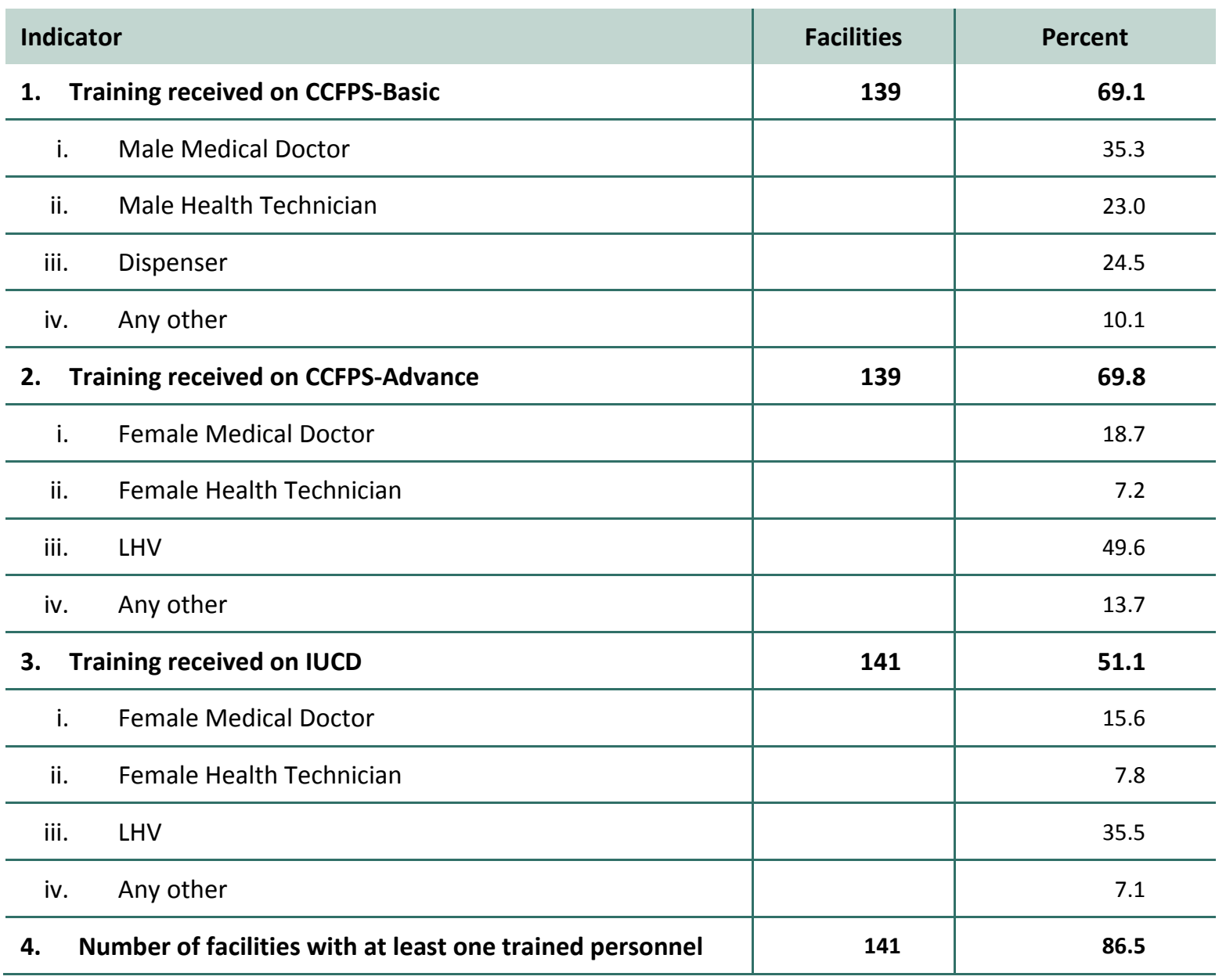

Multiple response variable

For CCFPS-Advance, survey findings show, at 70 percent of facilities, female staff was trained on CCFPS-Advance. At 50 percent of facilities, LHVs were trained on Advance, while at less than onefifth (18.7\%) of facilities female doctors were trained on Advance. At half of visited facilities (51\%), at least one female staff member was trained on IUCD insertion/removal. At 36 percent of facilities, LHVs were trained on IUCD skills (insertion and removal).

Trained staff is likely to better deliver health services (RamaRao and Mohanam 2003). FALAH has endeavored to help the public health sector overcome its quality of service and training deficit by training a number of health personnel for providing quality services (Table 2.3). Chapter 4 elaborates the impact of trained staff. 


\section{c) IEC Material Display}

As mentioned in Chapter 1, FALAH repositioned FP by promoting the concept of birth spacing for mother and child health benefits, and thereby developed a Behavior Change Communication (BCC) strategy. The BCC strategy focused on birth spacing and related concepts, supported by providing contraceptive posters (Tiahrt poster) to providers, which they are supposed to display at their facilities, as well as providing clinic-based counseling materials what are supposed to be utilized during client counseling sessions at facilities. These materials, especially those displaying information pictorially, can be very useful in rural settings with high levels of illiteracy.

Table 2.4 illustrates BCC material availability at facilities with trained and untrained providers. If a provider has ever been trained through FALAH, these BCC materials should be displayed and utilized; they are provided at training. As expected, 90 percent of facilities with trained staff, compared to 57 percent of facilities without trained staff, had BCC materials prominently displayed. This encouraging, compared with earlier study in which only 41 percent of FP clinics had pamphlets with information on contraceptive methods in Pakistan (Cernada et al. 1993).

Materials displayed at facilities mostly explained contraceptive methods ( $72 \%$ of facilities with trained providers compared with 59\% with untrained providers). Thirty-seven percent of facilities with trained staff and only 15 percent of facilities with untrained staff displayed materials on FP/birth spacing benefits, and 26 percent of facilities with trained staff, and only seven percent with untrained staff, displayed materials on benefits of pregnancy after age 18 and under 35 . Although HTSP material was available for trained providers, only one quarter displayed it.

Table 2.4: Percentage of facilities with availability of IEC material by training status*

\begin{tabular}{|c|c|c|}
\hline Indicator & \multirow{2}{*}{$\begin{array}{r}\text { Trained } \\
90.2\end{array}$} & \multirow{2}{*}{$\begin{array}{r}\text { Untrained } \\
57.1\end{array}$} \\
\hline 1. Facilities with IEC material displayed & & \\
\hline 2. Topics on IEC material displayed* & & \\
\hline i. Methods & 71.6 & 59.3 \\
\hline ii. Benefits of birth spacing/FP & 36.5 & 14.8 \\
\hline iii. Benefits of pregnancy after 18 and before 35 years & 25.7 & 7.4 \\
\hline iv. Abuses of pregnancy before 18 and after 35 years & 2.7 & 0.0 \\
\hline v. Tiahrt poster & 37.8 & 18.5 \\
\hline vi. Other & 28.4 & 44.4 \\
\hline
\end{tabular}

*Multiple response variable 
Table 2.5: Number and percent of facilities, by type and protocol of storage of contraceptives

\begin{tabular}{|c|c|c|c|}
\hline \multicolumn{2}{|c|}{ Indicator } & \multirow{2}{*}{$\begin{array}{r}\text { Facilities } \\
119\end{array}$} & \multirow[t]{2}{*}{ Percent } \\
\hline 1. $\mathrm{C}$ & eptives placed*: & & \\
\hline i. & In cupboard of staff's room & & 54.6 \\
\hline ii & In drawer & & 12.6 \\
\hline ii & In a separate store & & 14.3 \\
\hline is & In a separate store along with medicines & & 20.2 \\
\hline $\mathrm{v}$ & Any other place & & 7.6 \\
\hline 2. $\mathrm{P}$ & I for storage in a store being adopted*: & 34 & \\
\hline i. & Clean & & 47.1 \\
\hline ii & Cross- ventilated & & 41.2 \\
\hline ii & No direct sunlight on stored commodities & & 67.6 \\
\hline is & Supplies properly placed & & 38.2 \\
\hline v & Bin Cards affixed & & 38.2 \\
\hline
\end{tabular}

*Multiple response variable

\section{d) Contraceptive Storage}

Contraceptive storage plays an important role in ensuring its provision, in good condition. If contraceptives are not stored according to protocol, they can expire, be damaged or spoiled, and their efficacy can be undermined. During the visit, facility in-charges were asked where contraceptives were stored (Table 2.5). In most cases (55\%) contraceptives were stored in a staff's room cupboard, followed storage with medicines $(20 \%)$, and only 14 percent were placed in a separate store. Facilities tended to have either no supplies or very few supplies: hence the tendency to keep contraceptives in the cupboard in their room. Bin cards with expiration dates were found in only 38 percent of facilities; the absence of these can increase the risk of contraceptive expiration. The overall storage picture is not very encouraging.

\section{e) Facility FP Service Performance}

Information was collected on the number of FP/birth spacing clients and patients who had attended a facility in the last six months for assessing facilities' monthly performance for client attendance differentials. Information was collected from facility client attendance registers. As expected, the performance of facilities in which CCA-trained providers were available had significantly more FP clients than facilities in which CCA-trained providers were not available. 
Figure 2.2 clearly shows performance trend for the last six months in facilities with trained and untrained staff: In November 2011 facilities with trained providers were attracting almost 60 percent more clients than untrained provider facilities.

Figure 2.2: Average number of FP clients per facility, for last six months, by training status of facilities

\begin{tabular}{|cccccc|}
\hline 23.0 & 22.9 & 24.8 & 23.5 & 23.7 & 23.4 \\
18.4 & 15.6 & 14.9 & 13.2 & 16.2 & 14.6 \\
\hline Jun-11 & & & & \\
& Jul-11 & Aug-11 & Sep-11 & Oct-11 & Nov-11 \\
& & - Untrained & - Trained & & \\
\hline
\end{tabular}





\section{Chapter 3: Health Facility Functioning}

This chapter discusses the survey's findings from health provider interviews and helps determine facility readiness by assessing provider knowledge, counseling services, contraceptives supply, and client record-keeping and reporting, including side effects.

\subsection{Facilities with Trained Staff}

Figure 3.1 shows the percentage of facilities whose staff have any training including FALAH CCA training. Eighty-seven percent of facilities had at least one staff member trained by FALAH, while 69 percent of facilities' male staff was trained on CCFPS-Basic, 70 percent of facilities' female staff was trained in CCFPS-Advance, and 51 percent of facilities' female staff was trained in IUCDs.

Contraceptive logistics training was provided to staff dealing with medicine and contraceptive storage, as well as to a few providers; more than five percent of providers took contraceptive logistics training.

Figure 3.1: Percentage of facilities whose staff received training, by type of training received *

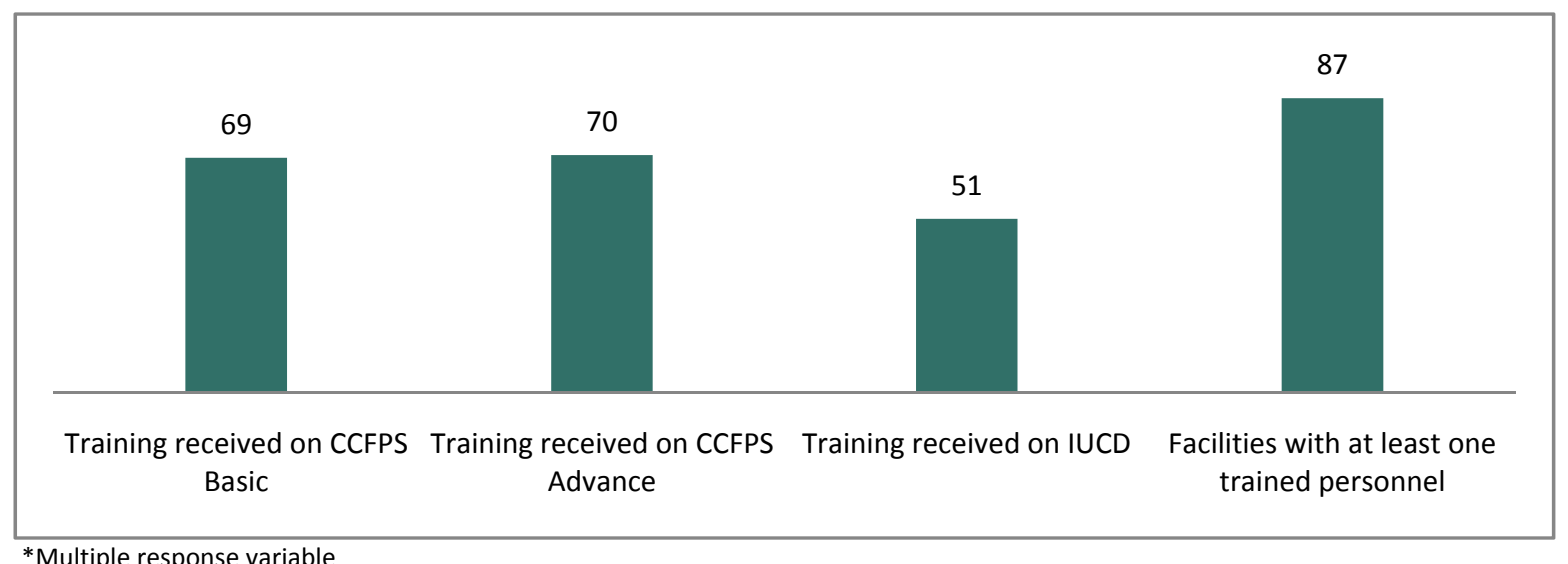

*Multiple response variable

\subsection{Service Provider Characteristics}

\section{a) FP Knowledge}

If providers have proper knowledge and understanding of FP/birth spacing concepts, they will better explain and counsel clients, and better provide FP/birth spacing services as well, based on clients' requirements. Female provider knowledge is particularly relevant, since most clients are women and only feel comfortable talking to female providers (Bruce 1990). In the survey, almost all providers interviewed were females. Moreover, in the analysis, knowledge differentials are presented by trained and untrained providers, for training impact. More than half (53\%) of those interviewed were trained, and rest, 47 percent, had no training by FALAH (Table 3.1). 
Table 3.1: Percentage of providers by knowledge of FP/birth spacing, according to training status

\begin{tabular}{|c|c|c|c|}
\hline \multirow[b]{2}{*}{ Characteristic } & \multirow[b]{2}{*}{$\mathbf{N}$} & \multicolumn{2}{|c|}{ Percent } \\
\hline & & Trained & Untrained \\
\hline Providers & 175 & 53.1 & 46.9 \\
\hline \multicolumn{4}{|l|}{ Knowledge } \\
\hline 1. Birth Spacing/FP is part of Health & 175 & 100.0 & 97.6 \\
\hline 2. Family Planning means: & 172 & & \\
\hline i. Plan your family according to your resources & & 78.3 & 50.0 \\
\hline ii. Small Family Norm & & 5.4 & 11.3 \\
\hline iii. Limiting the Children & & 7.6 & 26.3 \\
\hline iv. Limit up to two children & & 3.3 & 5.0 \\
\hline v. Any other & & 5.4 & 7.5 \\
\hline 3. Birth spacing means: & 171 & & \\
\hline i. Interval between children & & 22.8 & 48.1 \\
\hline ii. At least two years interval between two children & & 12.0 & 17.7 \\
\hline iii. At least three years interval between two children & & 22.8 & 21.5 \\
\hline iv. At least 24 months space between the one child and next & & 38.0 & 5.1 \\
\hline v. Any other & & 4.4 & 7.6 \\
\hline
\end{tabular}

FP miscomprehension has been considerable, with the general public interpreting IEC slogans such as Bachay do hee Acchay and Kam Bachay Khushhal Gharana as meaning they should limit their number of children. All those interviewed, however, expressed the belief that FP is part of health care. Twenty-six percent of untrained, and eight percent of trained, providers regard FP as limiting children. Among trained providers, 78 percent, and among untrained, 50 percent, of providers reported belief that FP means "Plan your family according to your resources."

FALAH promoted healthy timing and spacing of pregnancy (HTSP) and trained providers in HTSP, in which messages included pregnancy intention two years after preceding child birth, while earlier training had revolved around Optimal Birth Spacing Initiative (OBSI), which recommended three to five years birth intervals. Findings show HTSP birth spacing, "At least 24 months' space between the child birth and next pregnancy," was understood by 38 percent of trained, and five percent of untrained, providers, while a further 23 percent of trained, and 22 percent of untrained, providers understood the OBSI concept, "At least three years interval between two children." It appears providers are still influenced by OBSI's concept of FP, so the HTSP concept must be further emphasized, so providers can relate it to the two years of breastfeeding mentioned in the Holy Quran. 


\section{b) Counseling and Comprehensible Information}

Counseling should provide clients with information on FP/birth spacing and related topics, specifically mother and child health benefits. A range of options, including contraceptive methods, needs explanation, in accordance with client health compatibility. FP/birth spacing misconceptions and myths can be altered with sound argumentation. After a client has accepted $\mathrm{FP} /$ birth spacing, comprehensible information, meaning easily understandable, should be provided, and clients should then have detailed information on method use, side effects and management, effectiveness, and other necessary information. FALAH trained providers on all of these elements. Not even all trained providers provide such information to clients during counseling (Table 3.2). Although trained providers' emphasis now is on method use, effectiveness, and possible side effects, the most important aspect, handling side effects, is neglected, contributing to method discontinuation, which is higher among women not adequately counseled about side effects. In Gambia, 51 percent of clients not properly counseled discontinued use, compared with 14 percent who were well-counseled (RamaRao and Raji 2003). Counseling, so important for method continuation, is still weak in Pakistan. To increase FP clientele and improve its continuation, more training on counseling is needed, with sound knowledge and techniques.

Table 3.2: Counseling topic and comprehensible information, by training of provider

\begin{tabular}{|c|c|c|c|}
\hline \multirow[b]{2}{*}{ Services } & \multirow{3}{*}{$\begin{array}{c}\mathrm{N} \\
175\end{array}$} & \multicolumn{2}{|c|}{ Percent } \\
\hline & & Trained & Untrained \\
\hline 1. Counseling & & 98.9 & 93.9 \\
\hline 2. Counseling topics*: & 169 & & \\
\hline 1. Birth spacing & & 64.1 & 53.2 \\
\hline 2. Pregnancy before 18 and after 35 may be dangerous & & 8.7 & 3.9 \\
\hline 3. $\mathrm{FP}$ & & 77.2 & 74.0 \\
\hline 4. Inter-spousal communication & & 14.1 & 1.3 \\
\hline 5. Age at marriage & & 3.3 & 0.0 \\
\hline 6. Other & & 56.5 & 49.4 \\
\hline 3. Comprehensive information on*: & 169 & & \\
\hline 1. Availability of other methods & & 40.2 & 39.0 \\
\hline 2. How to use method & & 89.1 & 74.0 \\
\hline 3. Contraindications & & 21.7 & 24.7 \\
\hline 4. Effectiveness/duration of effectiveness & & 67.4 & 53.2 \\
\hline 5. Advantages compared to other methods & & 30.4 & 23.4 \\
\hline 6. Possible side effects & & 67.4 & 61.0 \\
\hline 7. What to do if experienced side effects & & 5.4 & 10.4 \\
\hline 8. Possibility of switching the method & & 6.5 & 10.4 \\
\hline 9. Any other & & 8.7 & 14.3 \\
\hline
\end{tabular}

*Multiple response variable 


\subsection{Contraceptive Stock}

The ultimate goal of the contraceptives logistics system is ensuring contraceptive availability at service delivery outlets so clients can procure their chosen methods during their planned visits to facilities. At facilities, those responsible for managing contraceptives should be trained in timely record-keeping of contraceptives logistics data, as well as submitting reports along with routine monitoring reports, and they need to ensure standard formats for record keeping and reporting are always available in their facilities. Logistics record formats are of no value unless they are complete, with accurate information, for making logistics decisions. In this situation analysis, contraceptive stocks and logs were observed in visited facilities.

\section{Contraceptive Availability, Recording, and Reporting}

Contraceptive availability in facilities is essential for FP service provision, especially in rural areas. Facility contraceptive availability was made possible by FALAH's efforts addressing contraceptive supply, by training district and facility health personnel on contraceptive logistics management. Sixty-nine percent of facilities in which at least one trained provider was available reported contraceptive availability during the facility visit, along with 64 percent at facilities where no FALAH-trained provider was available (Figure 3.2). To strengthen contraceptive supply, a series of field visits quantified contraceptive availability and identified potential problems if contraceptives were unavailable. Efforts were made to resolve supply issues on the spot or, if necessary, by involving higher management of the Health and Population departments, as well as PPHI ,EDOs (Health), District Support Managers of the PPHI program, LHW Program Coordinators, District Population Welfare Officers, and other related officers and staff, in particular LHVs (as focal persons for contraceptives in facilities). As a result, these survey findings show little difference between facilities with CCA-trained providers and those without them.

Figure 3.2: Percentage of facilities with contraceptive availability on the day of visit, by training status

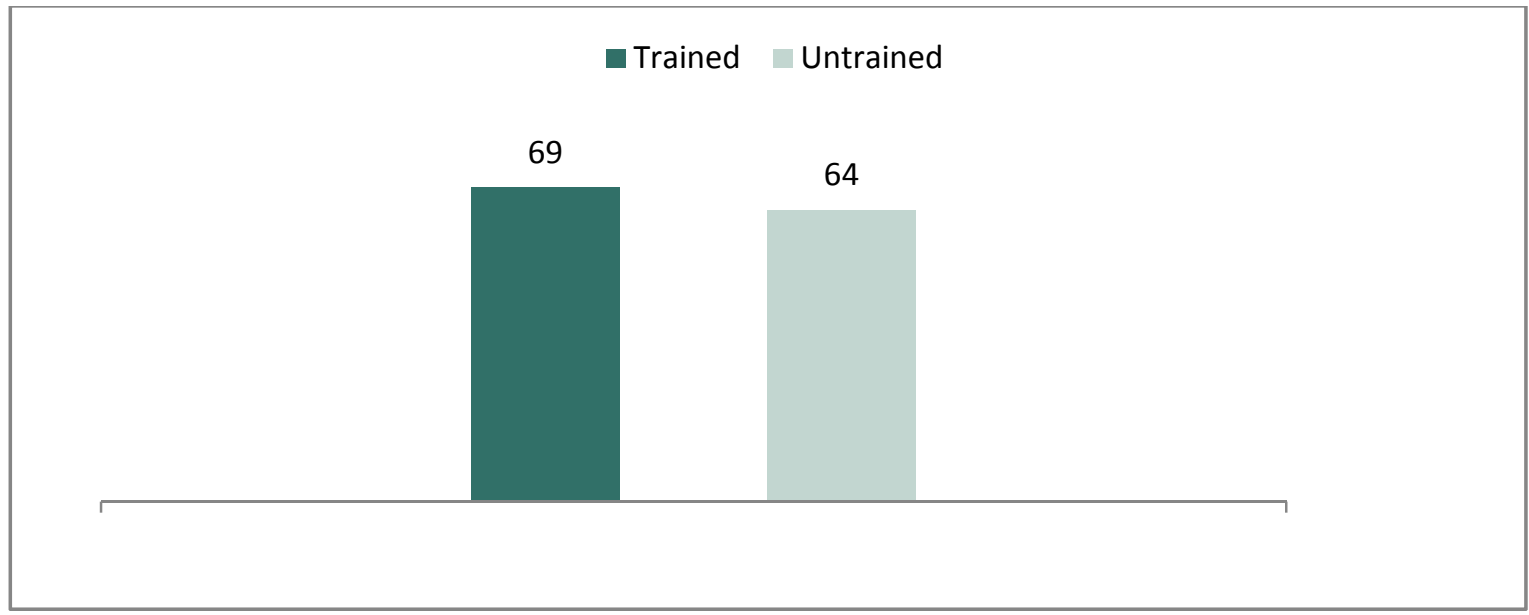


Almost one-third of visited health facilities did not have any contraceptives on the day of their visit (Table 3.3).District headquarter (DHQ) hospitals primarily comprised stocked out facilities. DHQ providers thought FP services were already available at RHS-A centers and, therefore, believed they did not need to stock contraceptive commodities. RHS-A centers, run by the Population Welfare Department, are on DHQ hospital premises and provide a full range of contraceptive methods, but only one quarter of health facilities reported contraceptive stocks of more than a month, while most had only a one month stock for every method. According to the contraceptive logistics manual, at least two months' buffer stock is required for the district store and facilities (Ministry of Population Welfare 2009).

During FALAH, central warehouse contraceptive stock was limited, so district contraceptive distribution was rationed (Ministry of Population Welfare 2010), but which resulted in a stock out.

Table 3.3: Usual contraceptive stock, by type of contraceptive and availability, and provider training status

\begin{tabular}{|c|c|c|c|}
\hline \multirow[b]{2}{*}{ Method } & & \multicolumn{2}{|c|}{ Percent } \\
\hline & & Trained & Untrained \\
\hline \multirow[t]{6}{*}{ i. } & Condom & & \\
\hline & a. No Stock & 32.0 & 38.5 \\
\hline & b. One month & 39.2 & 35.9 \\
\hline & c. Two months & 10.3 & 12.8 \\
\hline & d. Three months & 14.4 & 10.3 \\
\hline & e. More than three months & 4.1 & 2.6 \\
\hline \multirow[t]{6}{*}{ ii. } & Oral pills & & \\
\hline & a. No Stock & 32.0 & 35.9 \\
\hline & b. One month & 38.1 & 41.0 \\
\hline & b. Two months & 11.3 & 10.3 \\
\hline & c. Three months & 14.4 & 10.3 \\
\hline & d. More than three months & 4.1 & 2.6 \\
\hline \multirow[t]{6}{*}{ iii. } & Injectables & & \\
\hline & a. No Stock & 33.0 & 35.9 \\
\hline & b. One month & 34.0 & 43.6 \\
\hline & c. Two months & 10.3 & 7.7 \\
\hline & d. Three months & 17.5 & 10.3 \\
\hline & e. More than three months & 5.2 & 2.6 \\
\hline \multirow[t]{6}{*}{ iv. } & IUD & & \\
\hline & a. No Stock & 36.1 & 46.2 \\
\hline & b. One month & 32.0 & 33.3 \\
\hline & c. Two months & 9.3 & 7.7 \\
\hline & d. Three months & 18.6 & 12.8 \\
\hline & e. More than three months & 4.1 & 0.0 \\
\hline
\end{tabular}


The study also attempted to identify how providers try to minimize stock outs, and their outcomes. It is a point of satisfaction that 75 percent of trained, and 63 percent of untrained, providers immediately reported stock outs to in-charges; but even after their reporting, around 40 percent did not receive supplies, with almost one third arranging supplies from other sources.

In a well-designed contraceptive logistics system, facilities request contraceptives based on established inventory control (Government of Pakistan, 2007), with established maximums/minimums. When central warehouse stock is insufficient and supplies are rationed, facility stock outs are common. District DoH/PPHI also face stock outs due to central warehouse issues.

Table 3.3A: Type of action on stock outs and reporting result, by provider training status

\begin{tabular}{l|r|r|r} 
& & \multicolumn{2}{|c}{ Percent } \\
\cline { 4 - 4 } Indicator & $\mathbf{N}$ & Trained & Untrained \\
Action taken by providers: & 67 & & \\
\hline 1. Immediately reported to the In-charge & & 75.0 & 63.0 \\
\hline 2. Not reported & & 0.0 & 14.8 \\
\hline 3. Other & & 25.0 & 22.2 \\
\hline Result of reporting & 63 & & \\
\hline 1. Supplies received from EDO(Health)/PPHI & & 12.5 & 21.7 \\
\hline 2. Not received & & 42.5 & 39.1 \\
\hline 3. Arranged from other source & & 32.5 & 30.4 \\
\hline 4. Not resolved & 12.5 & 8.7 \\
\hline
\end{tabular}

The requisitioning system plays a critical role in contraceptive availability. System demand is initiated by health facilities (on a DOH-2 Form), through the EDO office, DoH and the district project office, PPHI. The EDO office and PPHI district manager requisition contraceptives from the central warehouse (CLR-6 Form) quarterly (Ministry of Population Welfare 2007).

Table 3.4: Method of submission of monthly contraceptive demand, by provider training status

\begin{tabular}{l|r|r}
\multirow{2}{*}{\begin{tabular}{l|r} 
Indicator for facilities submitting monthly contraceptive demand \\
1. DOH2 Form
\end{tabular}} & \multicolumn{2}{|c}{ Percent } \\
\cline { 2 - 3 } 2. Simple Paper & 76.3 & Untrained \\
\hline 3. Verbally & 6.2 & 64.1 \\
\hline $4 . \quad$ No & 4.1 & 18.0 \\
\hline
\end{tabular}

To make the system work efficiently, staff guidance on the requisitioning system was provided by FALAH and, as a result, instructions from EDOs (Health)/District Support Managers, PPHI to facility 
staff for requisitioning, and from higher levels to EDOs (Health). (Please see Annex-II) Table 3.4 shows that 76 percent facilities had started sending demands from facilities on DOH-2 Form where the providers were trained, compared to 64 percent of facilities where no provider was trained.

Most facilities report receiving fewer supplies than needed for all methods (Table 3.5). Slightly higher proportions of facilities with trained providers received fewer contraceptive supplies than facilities without trained providers, which is due to higher FP clientele in facilities where trained providers were available. Lower proportions of facilities reported supplies of injectables and IUDs commensurate with their demand, compared to condoms and oral pills. IUDs and injectables are only dispensed by health providers, however, whereas condoms and oral pills are available overthe-counter.

Table 3.5: Percentage of facilities, by contraceptive supply, compared to demand, according to training

\begin{tabular}{|c|c|c|c|c|}
\hline \multirow{2}{*}{\multicolumn{3}{|c|}{ Indicator }} & \multicolumn{2}{|c|}{ Percent facilities } \\
\hline & & & \multirow{2}{*}{$\begin{array}{l}\text { Trained } \\
64.9\end{array}$} & \multirow{2}{*}{$\begin{array}{l}\text { Untrained } \\
\qquad 66.7\end{array}$} \\
\hline \multirow{2}{*}{1.} & \multirow{2}{*}{ Condom } & According to demand & & \\
\hline & & Less than the demand & 35.1 & 33.3 \\
\hline \multirow{2}{*}{2.} & \multirow{2}{*}{ Oral pills } & According to demand & 64.9 & 66.7 \\
\hline & & Less than the demand & 35.1 & 33.3 \\
\hline & \multirow{2}{*}{ Injectables } & According to demand & 56.7 & 59.0 \\
\hline & & Less than the demand & 43.3 & 41.0 \\
\hline \multirow{2}{*}{4.} & \multirow{2}{*}{ IUD } & According to demand & 54.6 & 53.8 \\
\hline & & Less than the demand & 45.4 & 46.2 \\
\hline
\end{tabular}

Number of Facilities=136

Table 3.6: Contraceptive stocks and maintenance status of FP registers, by provider training status

\begin{tabular}{|c|c|c|c|}
\hline \multirow[b]{2}{*}{ Indicator } & \multirow[b]{2}{*}{$\mathbf{N}$} & \multicolumn{2}{|c|}{ Percent } \\
\hline & & Trained & Untrained \\
\hline Facilities maintaining contraceptive stock register & 136 & 72.2 & 64.1 \\
\hline Facilities maintaining contraceptive stock register regularly & 93 & & \\
\hline 1. Maintained and updated & & 87.0 & 83.3 \\
\hline 2. Maintained but not updated & & 5.8 & 16.7 \\
\hline 3. Not maintained & & 7.3 & 0.0 \\
\hline Facilities maintaining FP Client Register & 136 & 78.4 & 61.5 \\
\hline Facilities maintaining FP Register regularly & 98 & & \\
\hline 1. Maintained and updated & & 86.5 & 70.8 \\
\hline 2. Maintained but not updated & & 10.8 & 29.2 \\
\hline 3. Not maintained & & 2.7 & 0.0 \\
\hline
\end{tabular}


When contraceptives stock registers were examined, 72 percent of facilities with trained providers maintained their stock registers, compared to 64 percent of facilities without trained providers. Maintenance was slightly better at facilities with CCA-trained providers compared to facilities without CCA-trained providers. Similar results are seen in maintenance of FP client registers (78\% trained versus 62\% untrained) (Table 3.6).

\subsection{Client Load and Side Effect Reporting}

\section{a) Average Client Load}

The average number of FP clients for facilities for the month prior the survey is not encouraging; investigation is needed. It should be noted, however, that new clients outnumbered follow-ups.

Figure 3.3: Average FP client load per facility during last month $(\mathrm{N}=115)$

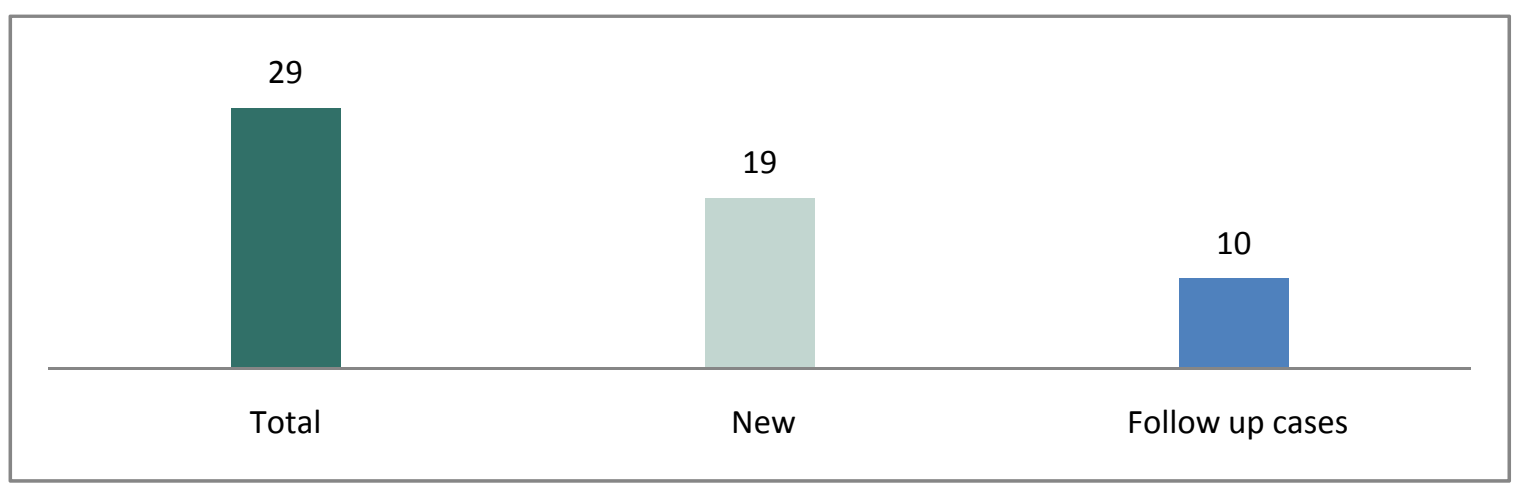

Trained providers had more clients, using all contraceptive methods except condoms (Table 3.7). Most clients, overall, choose injections, followed by the pill. Forty-six percent of trained, and 41 percent of untrained, providers received their last client on the day of visit. Among the 33 percent of trained, and 41 percent of untrained, providers who received an FP client during the last five days, flow was less, and so too for those who received their last client within the last 10 days. Worryingly, around 16 percent had not received any client during the past 10 or more days. There were small differences between trained and untrained providers in this regard. If no new client accepts family planning methods at a particular facility, this means counseling services at the facility are weak, and if no follow up visits, this could be due to non-availability of contraceptives at the facility among others. 
Table 3.7: Client load and duration since last FP client, by provider training status (Multiple Response Variable)

\begin{tabular}{l|l|l|l} 
& & \multicolumn{2}{|c}{ Percent } \\
\cline { 4 - 5 } Indicator & $\mathbf{N}$ & Trained & Untrained \\
Clients received last month by method: & 120 & & \\
\hline 1. Pills & & 84.2 & 81.8 \\
\hline 2. Injections & & 98.7 & 86.4 \\
\hline 3. IUD & & 60.5 & 52.3 \\
\hline 4. Condoms & & 53.9 & 63.6 \\
\hline Provider received last client: & 132 & & \\
\hline 1. On the same day & & 46.2 & 40.7 \\
\hline 2. Within last 5 days & & 33.3 & 40.7 \\
\hline 3. Within last 10 days & & 5.1 & 1.9 \\
\hline 4. More than last 10 days & & 15.4 & 16.7 \\
\hline
\end{tabular}

\section{b) Side Effect Reporting}

Minor side effects are common for most contraceptive users in the first few months of use, which concerns clients and is the biggest factor in contraceptive discontinuation. If proper side effect counseling is provided before contraceptive use, discontinuation rates can be reduced. Table 3.8 shows that trained providers received fewer clients with side effects compared to untrained providers for injectables and IUCDs, which shows that trained providers' clients were likely better prepared for side effects through their counseling.

Table 3.8: Average number of clients per provider who reported receiving clients for side effects, by method during last month and training status of providers

\begin{tabular}{|c|c|c|c|}
\hline \multirow{2}{*}{$\begin{array}{l}\text { Clients who reported side effects by method /per } \\
\text { provider during the last month }\end{array}$} & \multirow{2}{*}{$\begin{array}{c}\mathbf{N} \\
\text { (Providers) }\end{array}$} & \multicolumn{2}{|c|}{$\begin{array}{c}\text { Average number of clients per } \\
\text { provider }\end{array}$} \\
\hline & & Trained & Untrained \\
\hline 1. Pills & 17 & 2.3 & 2.3 \\
\hline 2. Injection & 88 & 2.8 & 3.1 \\
\hline 3. IUD & 33 & 1.6 & 3.1 \\
\hline 4. Condom & 5 & 1 & 1 \\
\hline
\end{tabular}

Table 3.9 shows that trained providers had fewer clients reporting serious side effects such as heavy bleeding (32\% of trained provider clients versus $63 \%$ of untrained provider clients), infection ( $2 \%$ for trained versus $16 \%$ for untrained), and IUCD expulsion ( $2 \%$ for trained versus $11 \%$ for untrained), signifying trained providers' proper client selection, appropriate counseling, observing proper infection prevention practices, and following proper insertion techniques. 
Table 3.9: Percentage of providers who received complications for side effects, by type of side effects according to provider training

\begin{tabular}{|c|c|c|c|}
\hline \multirow[b]{2}{*}{ Indicator } & \multirow[b]{2}{*}{$\mathbf{N}$} & \multicolumn{2}{|c|}{ Percent } \\
\hline & & Trained & Untrained \\
\hline Providers received complaints of side effects during last month & 166 & 87.8 & 85.5 \\
\hline Side effects commonly reported*: & 122 & & \\
\hline Heavy bleeding & & 32.3 & 63.2 \\
\hline Irregular bleedings & & 69.2 & 57.9 \\
\hline Weight gain & & 10.8 & 15.8 \\
\hline Weakness & & 12.3 & 12.3 \\
\hline Spotting & & 53.8 & 40.4 \\
\hline Infection & & 1.5 & 15.8 \\
\hline Nausea/giddiness & & 12.3 & 8.8 \\
\hline Headache & & 3.1 & 10.5 \\
\hline Backache & & 16.9 & 7.0 \\
\hline Allergy & & 4.6 & 3.5 \\
\hline Irritation & & 1.5 & 1.8 \\
\hline White discharge & & 9.2 & 10.5 \\
\hline IUD expelled & & 1.5 & 10.5 \\
\hline Pain in low abdomen & & 18.5 & 17.5 \\
\hline Body swelled & & 1.5 & 3.5 \\
\hline Others & & 9.2 & 12.3 \\
\hline
\end{tabular}

*Multiple response variable 


\section{Chapter 4: Quality of Care}

Quality of care refers not just to the technical competency, effectiveness, and care a provider offers clients but also the human aspect of care, "the way individuals and clients are treated by the system providing services" (Bruce 1990, Jain 1989). Quality of care for clients/patients at health facilities greatly influences whether they return and encourage or discourage others from doing so. In FP and RH services, quality of care has shown to increase contraceptive use (Creel et al. 2002).

Observations of client-provider interaction and client exit interviews help determine whether trained providers differed from untrained providers in client treatment, the findings of which are detailed in this chapter.

\subsection{Methodology}

In this study, 126 health facilities were surveyed, with 432 observations of client-provider interaction and an equal number of exit interviews. The objective of the observations was to note any differences in the treatment of clients by untrained and trained providers, while exit interviews aimed to grasp the client's level of satisfaction with the quality of care received.

Exit interviews were conducted with clients/patients immediately after their consultation with the provider, while their experience was fresh and they could express their views better than if the interviews were conducted at a later time. Exit interviews were conducted with the same patients/clients whose interactions with their providers were observed by the survey team at the selected public sector health facilities.

Providers included female doctors and health technicians, LHVs, midwives and nurses (in case they are service providers), both trained and untrained in CCFPS-Advance and IUCD insertion and removal. During the observations providers were assessed on their technical expertise, with special attention to their compliance with the SAHR framework, a component of FALAH's CCFPS training developed by Population Council helping providers holistically assess client RH needs and provide a range of suitable options (Sathar et al. 2005).

\subsection{Findings}

\section{a) Client salutation}

Salutation stresses the need for greeting clients with respect, building rapport, and ensuring confidentiality so clients can comfortably discuss their problems with their providers. Figure 4.1 
shows the differentials for the various aspects of salutation, including how the client is welcomed, shown respect, and displays confidence in free and open discussion about her problems, considering the provider as a friend. There were marked differences in each 'salutation' component between trained and untrained providers, with the former performing much better. Particularly marked was the difference between asking 'ice-breaker' questions and reassured about confidentiality; these two aspects can significantly affect consultation quality, as they determine how comfortable clients feel about discussing their problems with providers.

Figure 4.1: Impact of SAHR training component 'Salutation' on provider behavior and interaction with clients by their training status

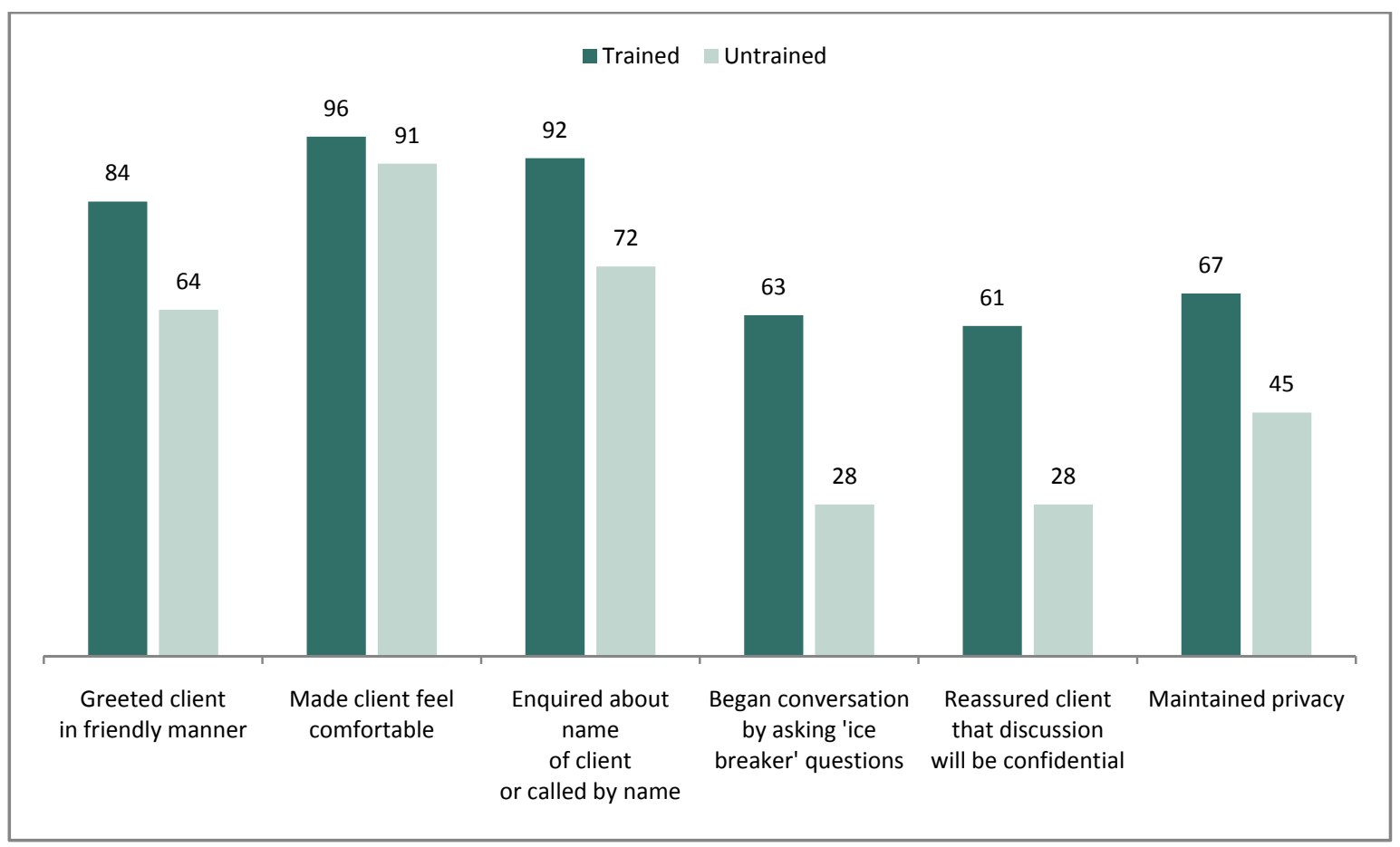

\section{b) Assessment}

Assessment aims to not only understand the immediate medical issues clients present but also place these issues within a proper context. Providers must listen attentively and give enough time to clients, taking care not to dismiss or disregard anything clients might want to report. A holistic approach must be adopted by providers for identifying the social contexts of client issues and needs. Permission must be sought before any examination, and results must be explained. 
Figure 4.2: Impact of SAHR training component 'Assessment' on provider behavior and interaction with clients, by provider training status

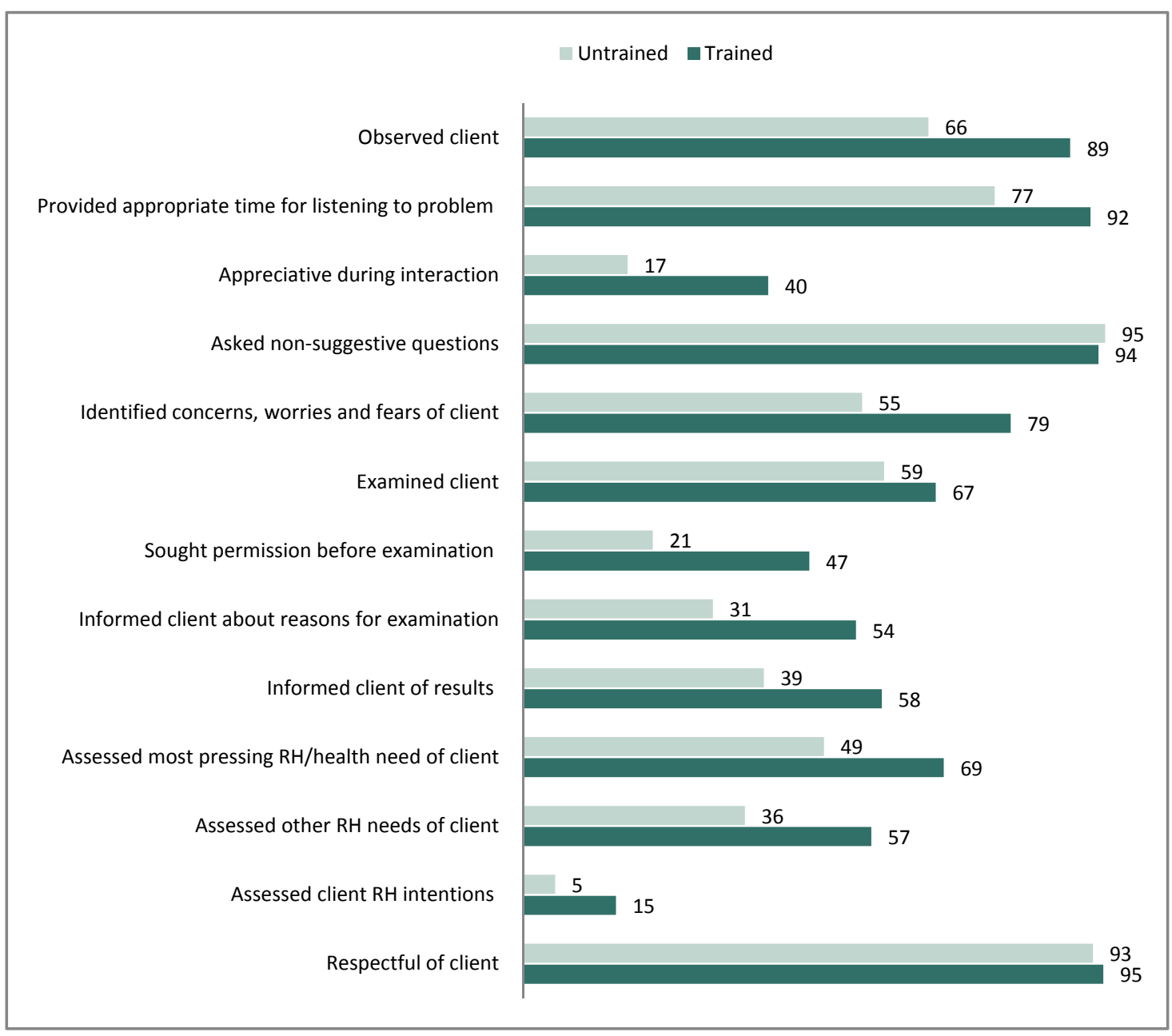

This is the second step, after salutation, and aims to maintaining client/patient confidence by creating a friendly atmosphere so they can openly discuss their issues, which helps providers making real judgments and assessments. Client/patient assessment satisfaction is a pre-requisite for treatment. Figure 4.2 provides client satisfaction with trained and untrained provider treatment during their assessments. Observations of client-provider interactions show that both trained and untrained providers generally were not dismissive towards clients, but trained providers, however, were better at devoting sufficient time to listening to client problems and assessing clients' other RH needs. Trained providers were also better in identifying client concerns and fears than untrained providers. Both trained and untrained providers scored the least in assessing clients' RH intentions, with the indicator "assessment of most pressing $\mathrm{RH} /$ health need of client" also requiring "more attention" from both provider cadres. 


\section{c) Help}

The provider must offer and explain the range of options and choices available for clients' needs, for example, suggesting medicines (or FP methods) or providing advice and answers to any questions clients may have. If necessary, providers must also refer clients to appropriate higher level facilities and provide comprehensive information. This is the third step, and after assessment/examination and client/patient diagnosis, providers prescribe treatment by suggesting medicine or providing advice. Figure 4.3 shows how trained and untrained providers perform in helping clients understanding their treatment. It is encouraging that the vast majority of providers maintain an atmosphere encouraging clients to speak; however, again, trained providers performed better than untrained providers in almost all elements. Trained providers are far ahead of their untrained colleagues in providing clients with a range of FP options. Both trained and untrained providers make very few referrals, though the former are significantly better in guiding clients/patients on where to go when referrals are made. However, in providing information about medicine dosage, time of use, and possible side effects, trained providers lag slightly behind untrained providers.

Figure 4.3: Impact of SAHR training component 'Help' on provider behavior and interaction with clients, by training status

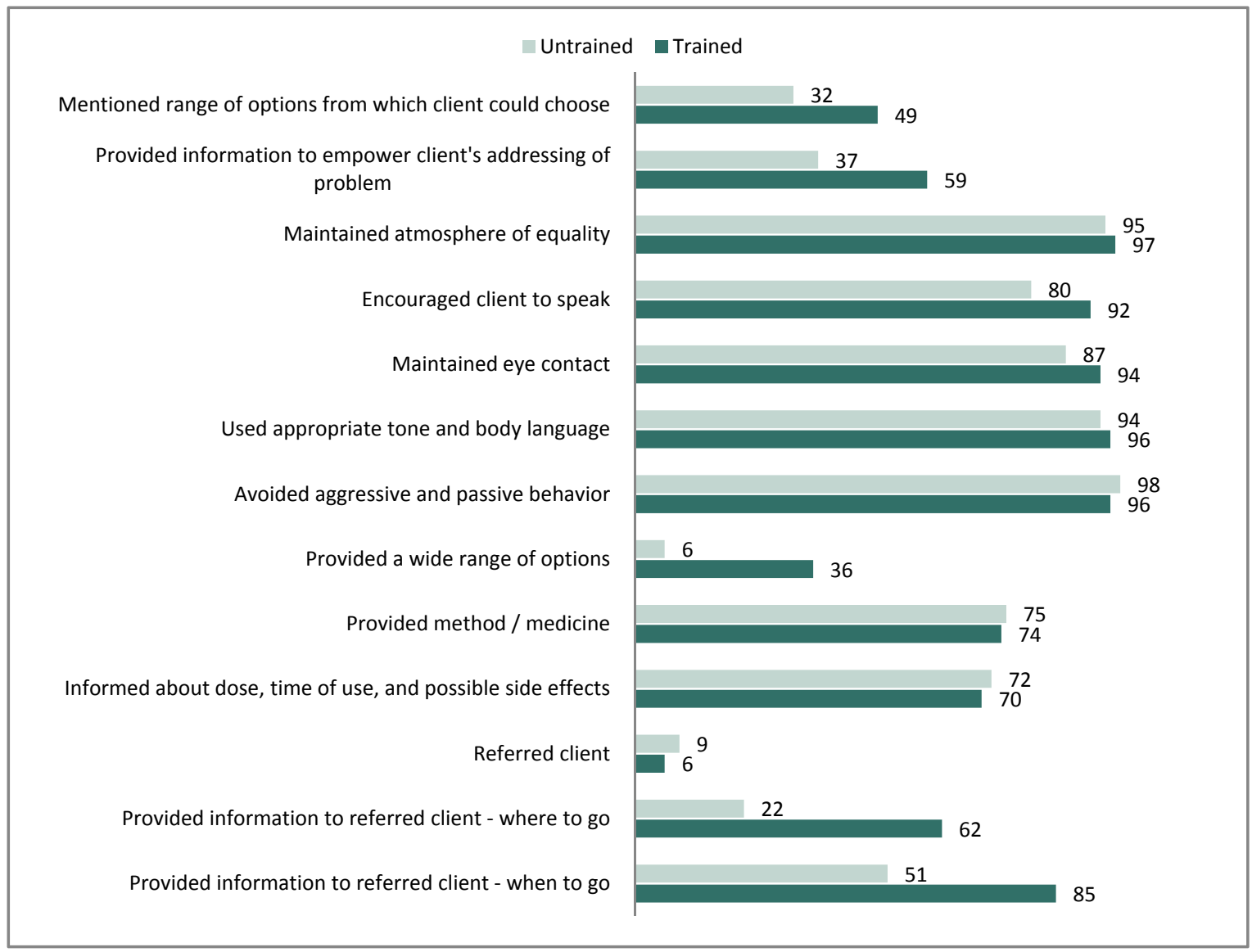




\section{d) Reassurance}

The provider must make sure that the client has understood what has been explained to him regarding treatment and prescription (including the next appointment if necessary). The provider should reassure the client that in case of any problem the solution provided to him can be renegotiated and that he can approach the provider any time if the original problem persists. As the last step for provision of quality services providers are expected to reassure clients about the treatment suggested. They must also themselves be assured that the client/patients have understood the treatment and prescription; making this effort will further increase the confidence of the client in the provider, thereby encouraging them to make use of the services again and recommend these to others. As seen in Figure 4.4 below trained providers do better than untrained providers in allaying clients' fears and reassuring them and advising on follow-up visits. However, both trained and untrained providers were weak in reassuring clients that if their condition does not improve they can return for a consultation to discuss other options. They were also paying less attention by asking clients to repeat instructions given by them.

Figure 4.4: Impact of SAHR training component 'Reassurance' on provider behavior and interaction with clients by their training status

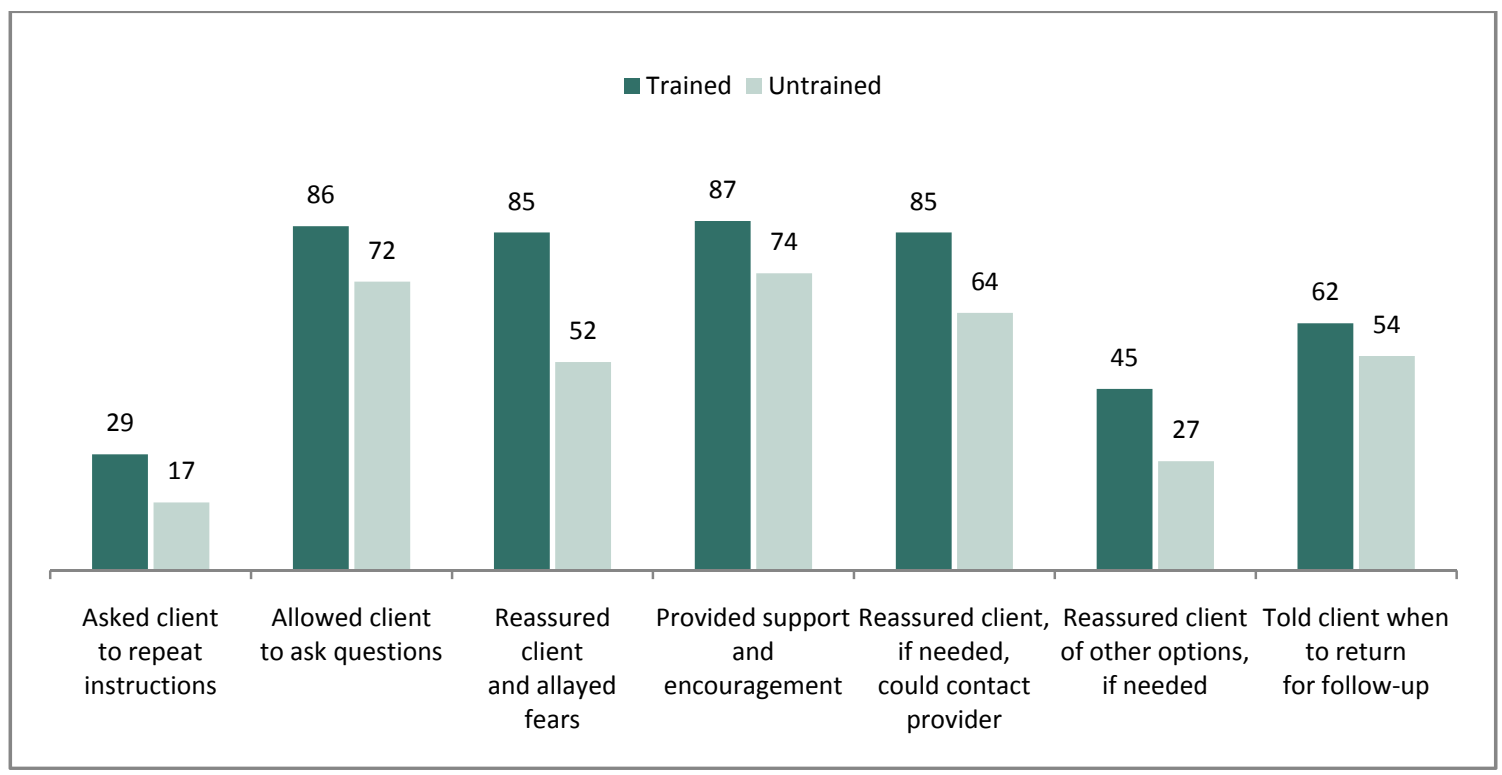




\subsection{Client Satisfaction: General Patients}

Clients have a right to information for appropriate, informed $\mathrm{RH}$ decisions, and providers should respect their dignity and confidentiality (Rudy et al. 2003). Client-provider interaction includes all face-to-face communication between clients and service providers. Counseling is the most important form of client-provider interaction, with a specific purpose requiring special knowledge and skills. Client satisfaction may not necessarily mean quality is good; it can indicate low client expectations instead (Liz et al. 2002).

\section{a) Treatment Seeking}

The distribution of clients interviewed shows the majority of interviewees were from BHUs (44\%), followed by RHCs (34\%) (Figure 4.5).

Figure 4.5: Percentage of clients/patients, by type of facility consulted for usual treatment

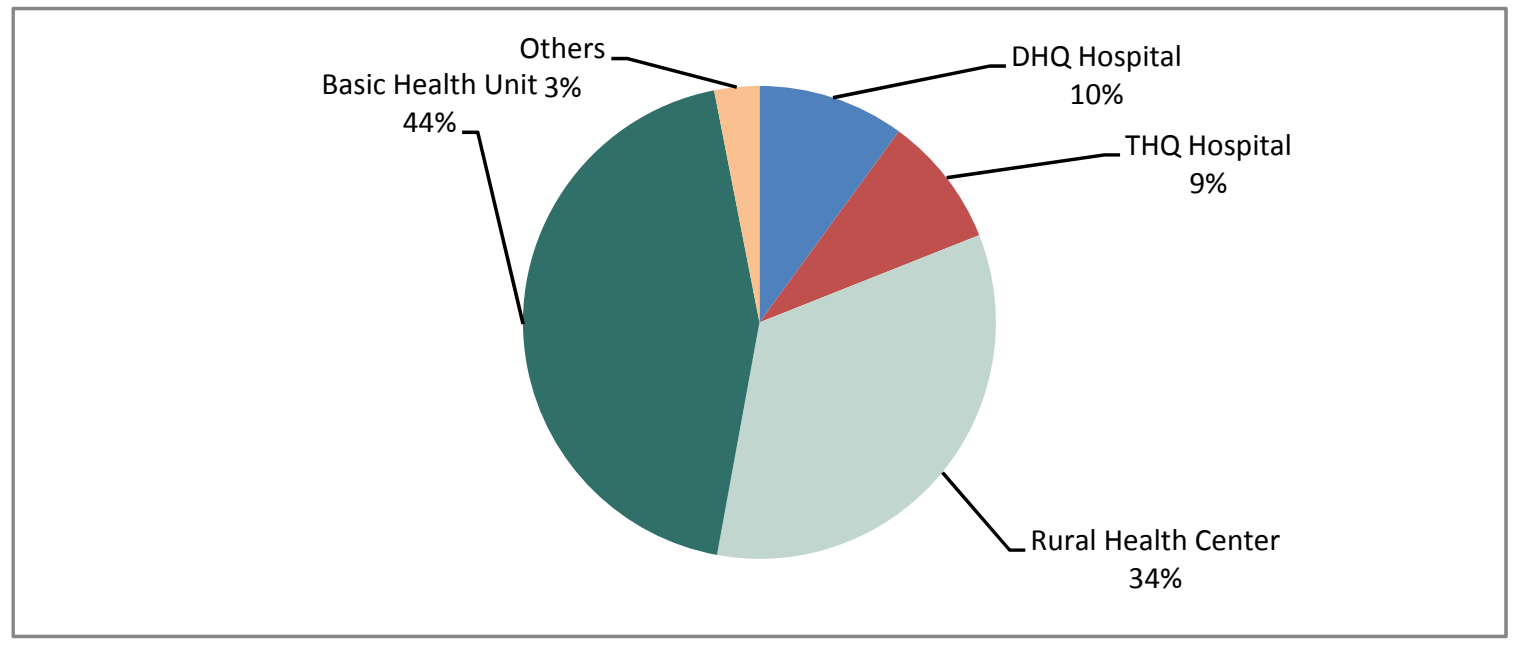

\section{b) Female empowerment for Visiting Health Facilities}

Women's visits to health facilities can help reduce morbidity and maternal mortality and also presents opportunity for FP use/ adoption, through counseling. Table 4.1 details the percentage of clients/patients, distributed by individuals advising clients/patients and determining their health facility visits. It is encouraging to note, while almost half of women (46\%) decided jointly (in consultation with other family members) to visit a facility, one quarter (25\%) made the decision on their own. Further, 30 percent of women said they chose that particular facility on their own, followed by 25 percent who chose the facility jointly with the family, and 18 percent came on their husband's advice. 
Table 4.1: Percentage of client/patient health decision-making and advice

\begin{tabular}{l|c|c} 
Decision/Advice by & By decision * & By advice \\
Self & 24.5 & 29.9 \\
\hline Husband & 19.2 & 17.6 \\
\hline Jointly & 46.4 & 25.2 \\
\hline Mother & 5.3 & 6.5 \\
\hline Mother in law & 7.1 & 8.3 \\
\hline Sister in law & 1.1 & 4.5 \\
\hline Other & 5.7 & 8.0 \\
\hline *Multiple response variable & & 2
\end{tabular}

Women's mobility is restricted in Pakistan. Earlier studies on their access to health services have emphasized restricted mobility's role as a major impediment (Sathar and Kazi, 1997; World Bank 2005). In Figure 4.6, the distribution of women clients, by person accompanying them to the health facility, shows only 10 percent visiting facilities on their own. Women patients require someone to accompany them even to visit a heath facility. Findings show that 43 percent of patients visited the facility with a female relative, while 23 percent were accompanied by their husbands. Visiting a health facility with their husband can also encourage spousal communication.

Figure 4.6: Percentage of clients/patients accompanied to health facility

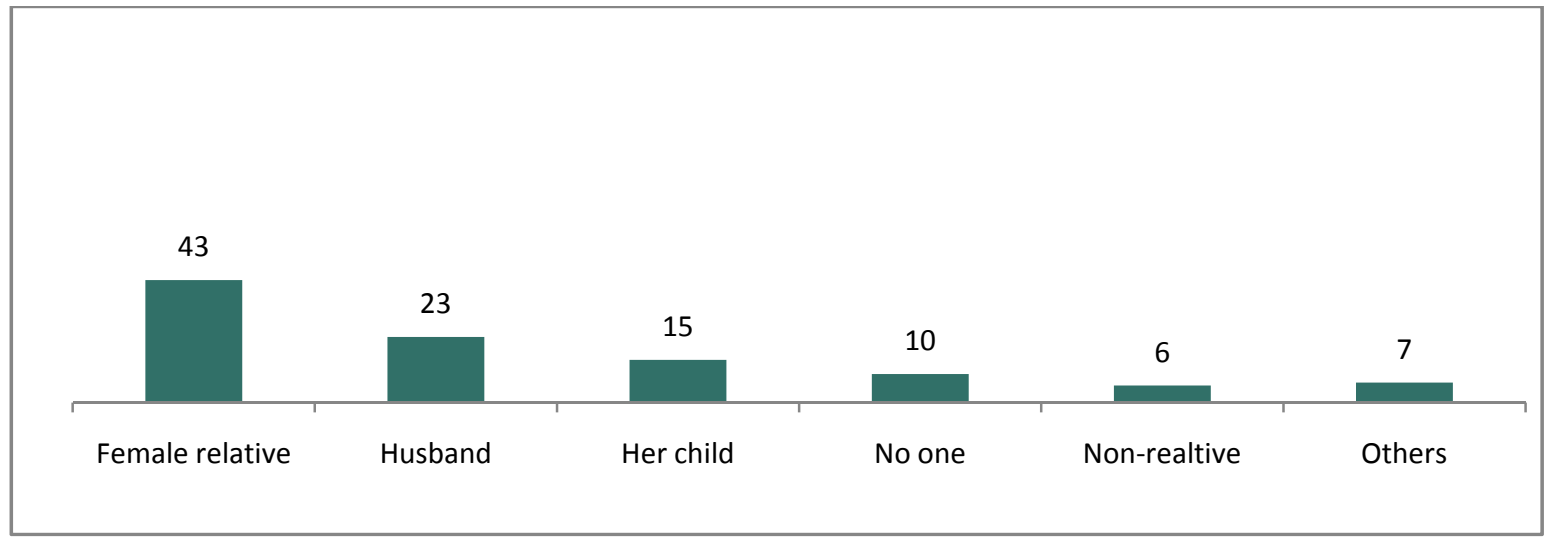

Multiple response variable

\section{c) Travel to Health Facilities}

Travel to health facilities affects treatment seeking and health facility access. Many women cannot easily get to health facilities, which often are far apart. Even if public transportation is available, traveling alone may not be socially acceptable for women. Furthermore, traveling long distances may make it difficult for some women to obtain services secretly. 
Over one quarter (28\%) of interviewees could reach a facility within 10 to 19 minutes, and 54 percent within half an hour, but for a further near quarter $(23 \%)$, travel took an hour or more (Figure 4.7). As discussed earlier, a number of women bypassed BHUs and traveled to RHCs, with most probably seeking quality services or female staff. Quality services within easy access of women would increase their utilization and help ensure patient needs are satisfactorily met.

Figure 4.7: Percentage of clients/patients, by time taken to reach health facilities

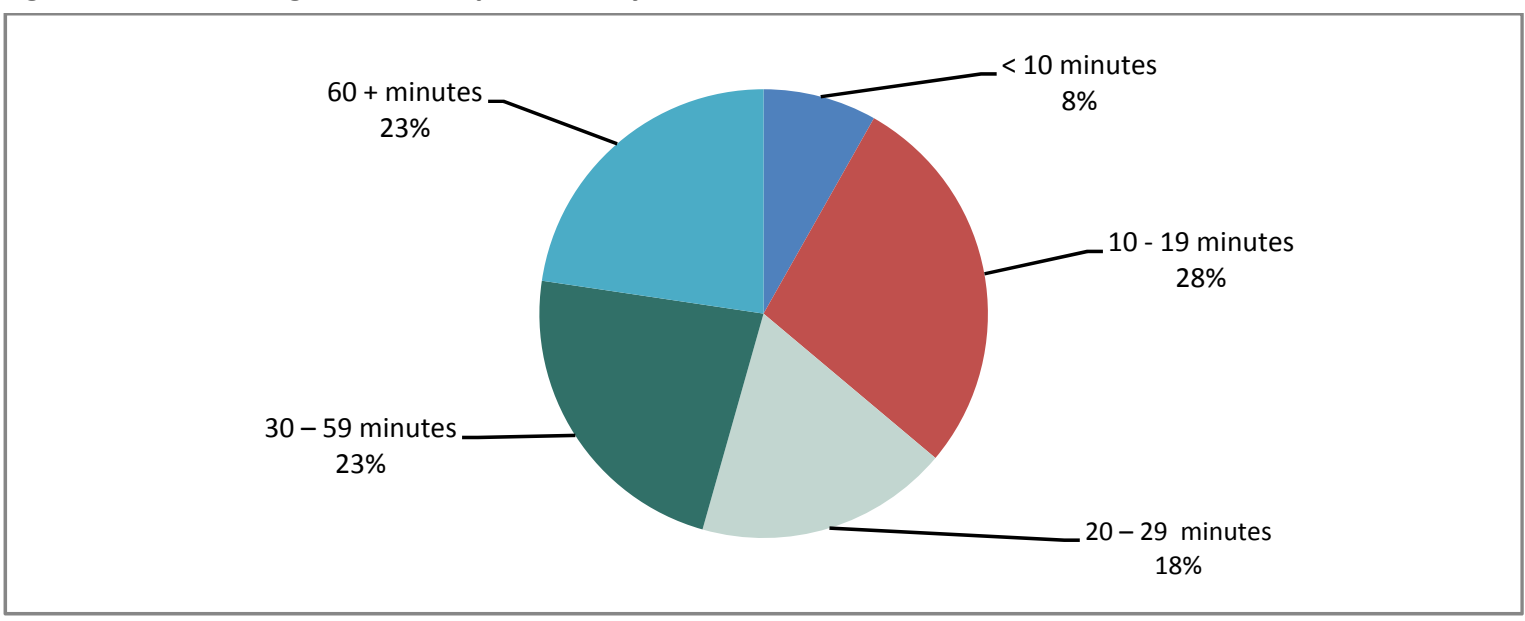

Fifty-four percent of patients reached health facilities on foot, followed by 29 percent by rickshaw or motorcycle (Figure 4.8). Other means of travel are not common. For over half of women there is no financial transportation cost in accessing health facilities and, for the most part, facilities are within walking distance. A small percentage does incur some travel costs.

Figure 4.8: Percentage of client/patient means of travel to health facility

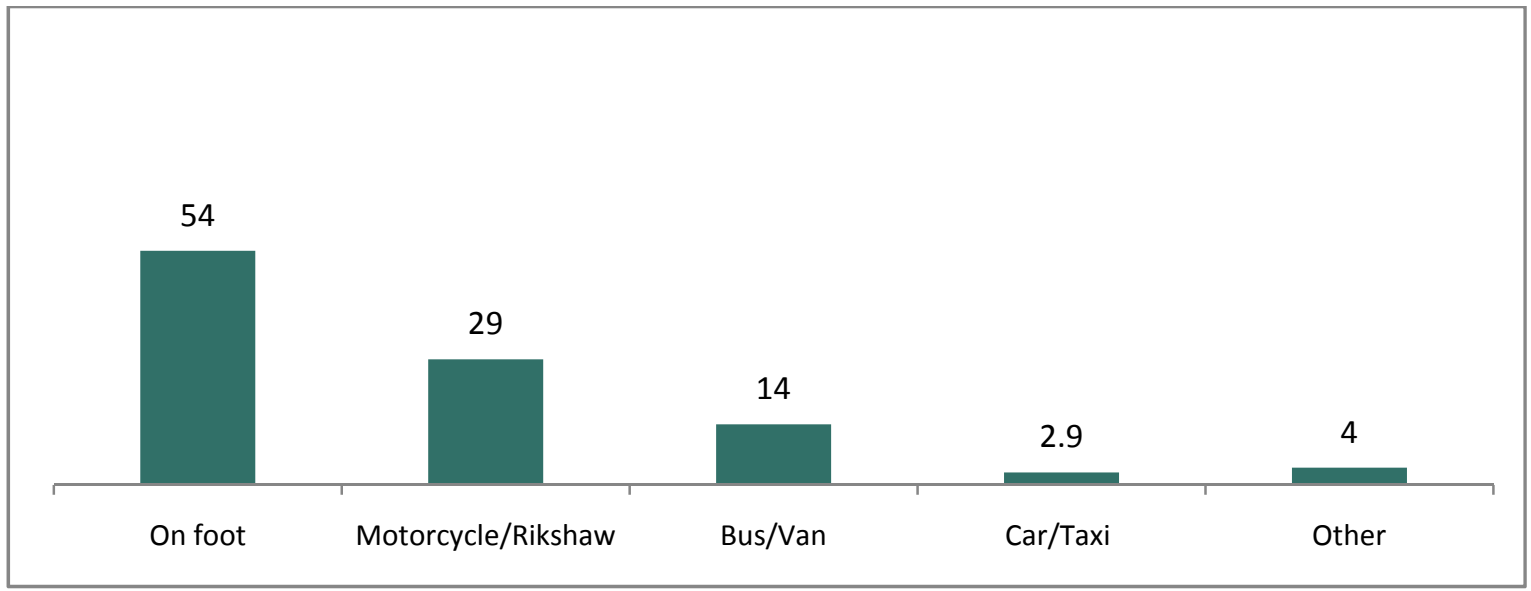




\section{d) Service cost}

Service cost also determines whether people seek services, specifically FP services. Findings show, overall, only 37 percent of clients/patients reported paying service fees. In Pakistan's health facilities contraceptives are free, but in some cases (Table 4.2) nominal charges are paid by clients. Of those paying the most (89\%) paid up to Rs. 5, the regular purchee (registration) fee at public health facilities. Health services and consultations at government facilities are free, but laboratory services are not. The vast majority (92\%) of clients/patients found services affordable, which means cost is not an issue in public sector health service utilization ( Figure 4.9).

Table 4.2: Percent of patient payments, by cost

\begin{tabular}{l|c} 
Rupees paid & Percent Clients/Patients \\
$1-2$ Rs. & 33.5 \\
\hline $3-5$ Rs. & 55.3 \\
\hline $6-50$ Rs. & 8.1 \\
\hline$>$ Rs. 50 & 3.1 \\
\hline Total & 100 \\
\hline
\end{tabular}

Figure 4.9: Percentage of clients/patients by opinion about service affordability

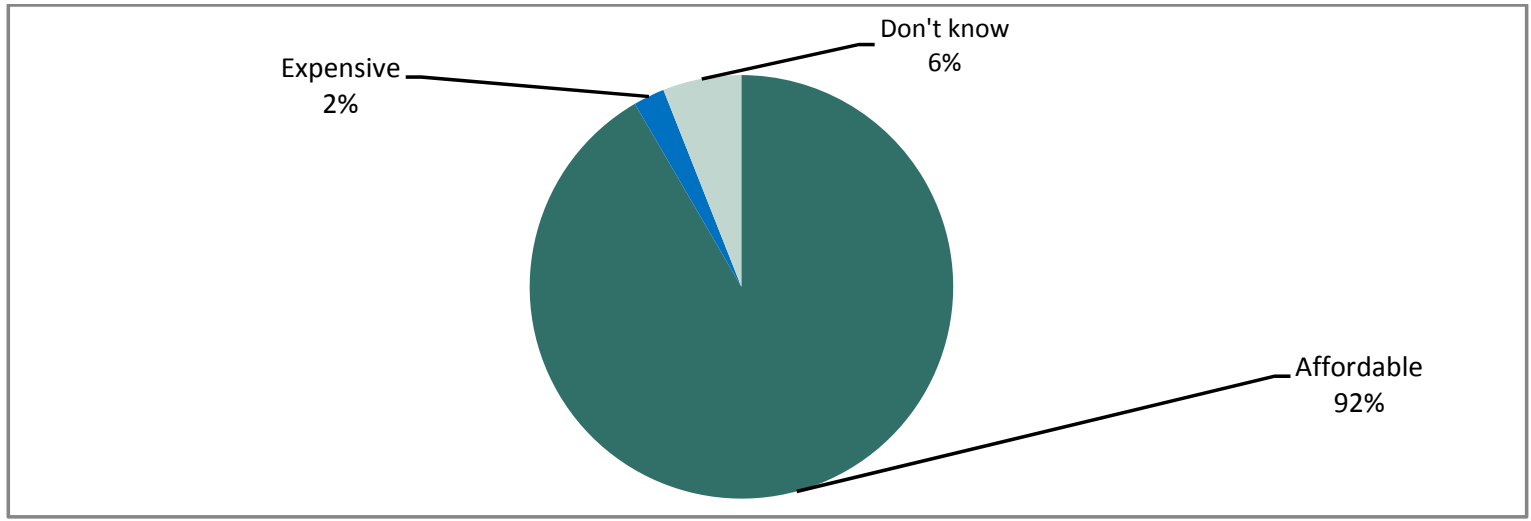

A waiting area (Table 2.1) was available at 95 percent of facilities. Seating arrangements are essential for client/patient ease and comfort, especially for old and pregnant women. Almost 97 percent of interviewees reported that seating was available at their facility. 


\subsection{Client Satisfaction: FP Clients}

The most common reason for FP client visits to facilities was method adoption, followed by resupply, side effect complaints, and method change; discontinuation visits were negligible. Disaggregation of visit objectives by trained and untrained providers showed considerable similarity: Trained providers received more visits for method adoption and change, while untrained providers received more visits relating to side effects (Figure 4.10). Contraception discontinuation is mainly due to side effects (Naz and Mahmood 2012). Clients with problems or concerns should be given careful attention and counseling, and not just for clients with side effects, but also for new clients for method adoption, with whom providers should discuss potential side effects proactively and take concerns about side effects seriously. Clients should also express concerns, needs, and preferences. About one third of clients at facilities returned for follow-up or contraceptive re-supply. Most are satisfied clients with no particular problems or concerns, with about 10 percent attending facilities to change contraceptive method due to dissatisfaction.

Figure 4.10: Percentage of clients by the objective of visit to facilities for family planning according to the training status of providers

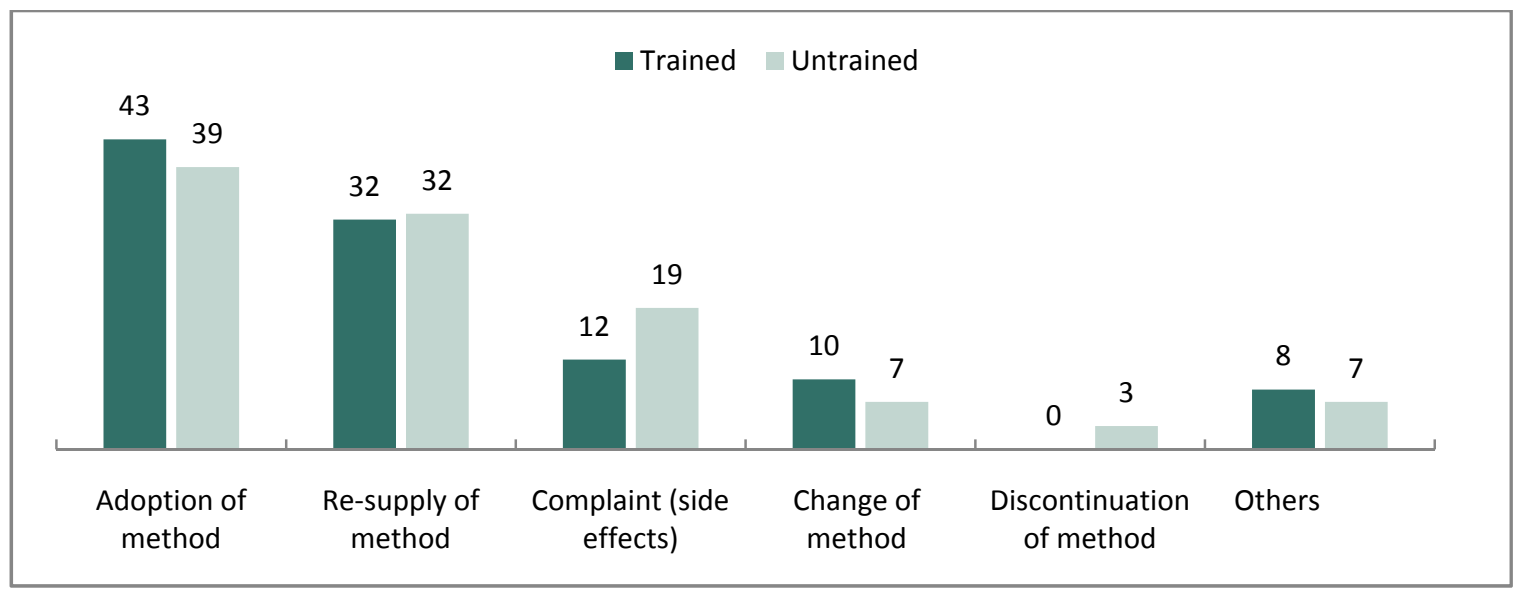

Multiple response variables

Overall, FP clients were satisfied with provider interaction and opportunity to discuss their issues, yet their responses were somewhat less positive for untrained providers' understanding of their problems. There were also marked differences for provider attitude towards clients: While trained providers have an inviting attitude, 12.5 percent of untrained providers were reported to as dismissive towards clients. In general, for new clients, most already have a method in mind. For those who need help selecting a method, the provider should explore the client's personal situation, RH intentions, and method preference, if any, and then fill any knowledge gaps and correct any misperceptions (Rudy et al. 2003). Table 4.3 shows that 46 percent of clients of 
trained, and 39 percent of clients of untrained, providers reported questions exploring their personal situations and examination as well, and further, 43 percent of clients of trained, and 42 percent of clients of untrained, providers were also asked questions but were not examined. It is possible, however, that these unexamined clients did not need an examination. One tenth of clients of untrained providers, compared to three percent of clients of trained providers, reported providers not asking any questions about their situation nor examining them.

Table 4.3: Percentage of client assessments, by type and provider training

\begin{tabular}{l|c|c} 
Provider assessed the problem as: & Trained & Untrained \\
Did nothing & 2.8 & 9.7 \\
\hline Examined only & 2.8 & 6.5 \\
\hline Asked only & 43.1 & 41.9 \\
\hline Both asked and examined & 45.8 & 38.7 \\
\hline Client description & 5.6 & 3.2 \\
\hline
\end{tabular}

For clients who were examined, permission by trained providers was sought for 72 percent of their clients, and 53 percent of untrained provider clients, while 73 percent of clients visiting trained providers and 60 percent of clients of untrained providers were informed of the reasons for their examination. Providers must get permission prior to examination and provide essential information clearly, in terms clients can understand. Some clients from whom permission was not sought, nor reasons given, possibly needed only minor examinations such as checking blood pressure. Eighty percent of clients were provided their examination results by trained providers, but untrained providers only offered results to 67 percent of their clients (Figure 4.11).

Figure 4.11: Percentage of clients informed about examination, by training of providers

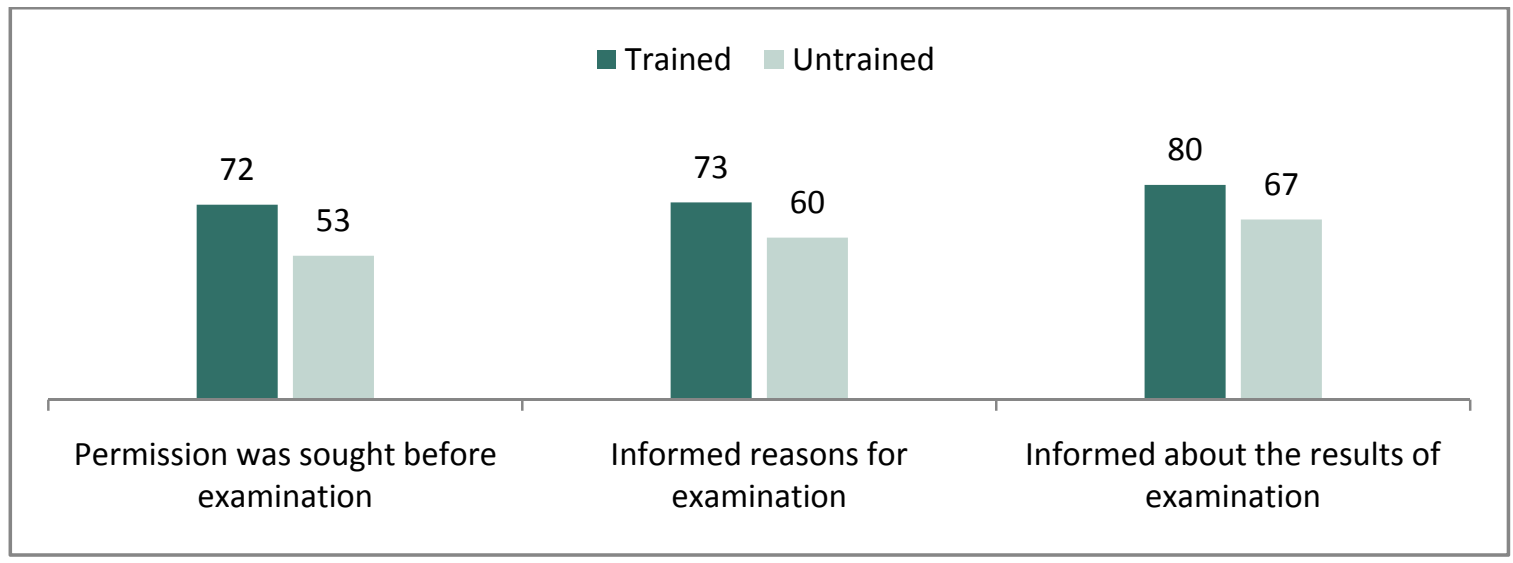


While just over a quarter of respondents never used any contraceptive method at the time of the exit interview, almost 50 percent used contraception, and just under a quarter were prior users.

Figure 4.12: Percent contraception use at exit interview

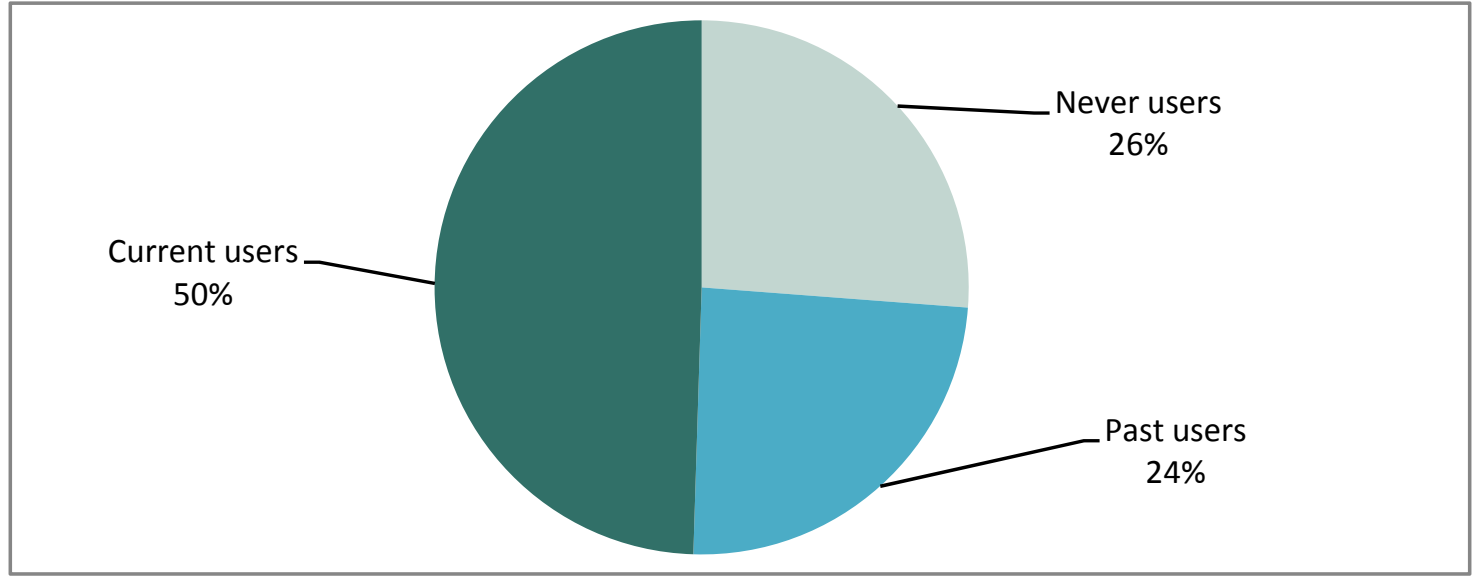

A provider can help an FP client in several ways: For new FP users, the provider must give all necessary and relevant information on available FP methods, and if the client has come for resupply, the provider should ask about and address any problems the client/patient may be facing with the current method, and recommend another method if appropriate.

Sixty-seven percent of clients attended by trained, and 52 percent clients attended by untrained, providers confirmed being asked about problems with their current FP method, and 69 percent of clients of trained, and 52 percent of clients of untrained, providers had possible reasons for their problems explicated. While 88 percent attended by trained providers, and 46 percent of clients attended by untrained provides, were advised about more than one FP method, exit interviews confirmed that trained providers provide more information to FP clients compared to untrained providers (Figure 4.13).

Figure 4.13: Help for clients, by percent of clients of trained and untrained providers

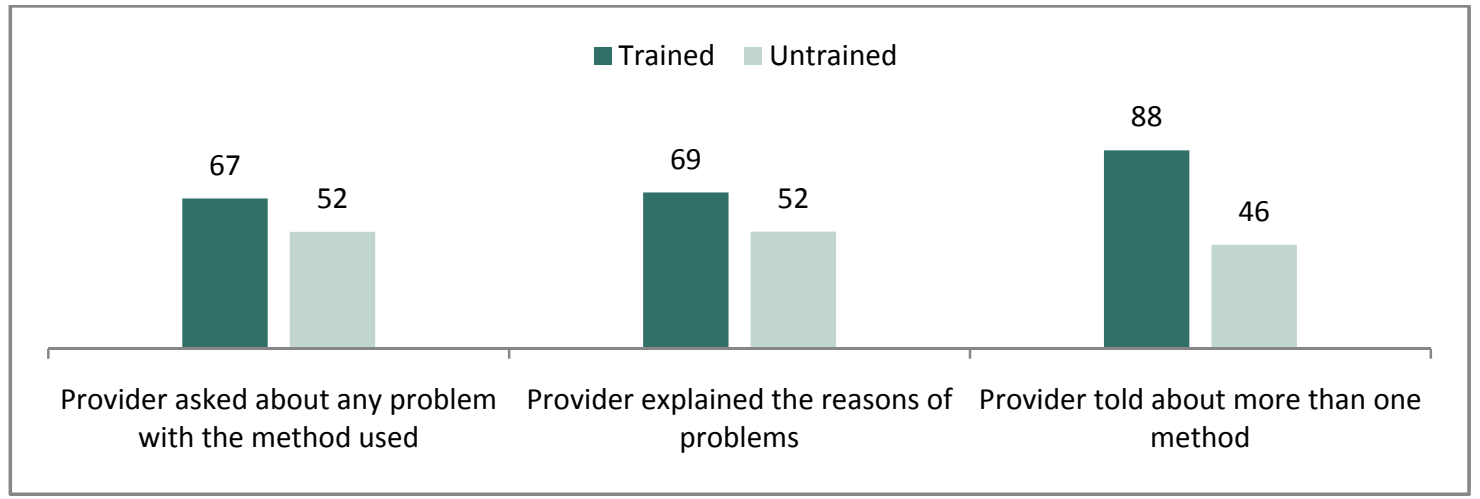


Discussions about counseling usually focus on helping the "new" client choose an FP method. According to clients interviewed, almost half (48\%) stated they did not receive any information from untrained providers about FP methods, and only more than a quarter (28\%) received information on side effects. A vast majority (95\%) of clients sought information on FP methods from trained providers, but only 56 percent received information on possible side effects from them. Fifty-four percent of clients were informed about new method duration and effectiveness by trained providers, but only about one quarter received this information from untrained providers. During method adoption, counseling that helps clients choose and learn to use a method that suits them has a positive impact on method adoption, continuation, regimen compliance, and resulting health outcomes (Rudy 2003).

Table 4.4: Percentage of clients provided FP information, by type of information and provider training

\begin{tabular}{l|r|r} 
Information provided about FP method/s & Trained & Untrained \\
Nothing & 5.1 & 48.0 \\
\hline Pros and cons of method(s) & 8.5 & 4.0 \\
\hline How to use method & 32.2 & 16.0 \\
\hline Effectiveness-duration & 54.2 & 28.0 \\
\hline Effectiveness-level & 6.8 & 4.0 \\
\hline Possible side effects & 55.9 & 28.0 \\
\hline Ability to protect from STDs & 3.4 & 0.0 \\
\hline Others & 6.8 & 0.0 \\
\hline
\end{tabular}

Multiple response variables

If clients can obtain needed treatment at the same facility at which they are assessed, this increases chances they will utilize health services and recommend them to others. Moreover, local (BHU) method or treatment availability can stop patients from going to higher-level facilities, thereby easing their patient load. The study found, for trained providers, 81 percent of clients/patients obtained their necessary treatment or method at the same place, while this was true for only 73 percent of clients/patients of untrained providers (Figure 4.14).

Figure 4.14: Percentage of clients reporting availability of method by the status of training of the provider

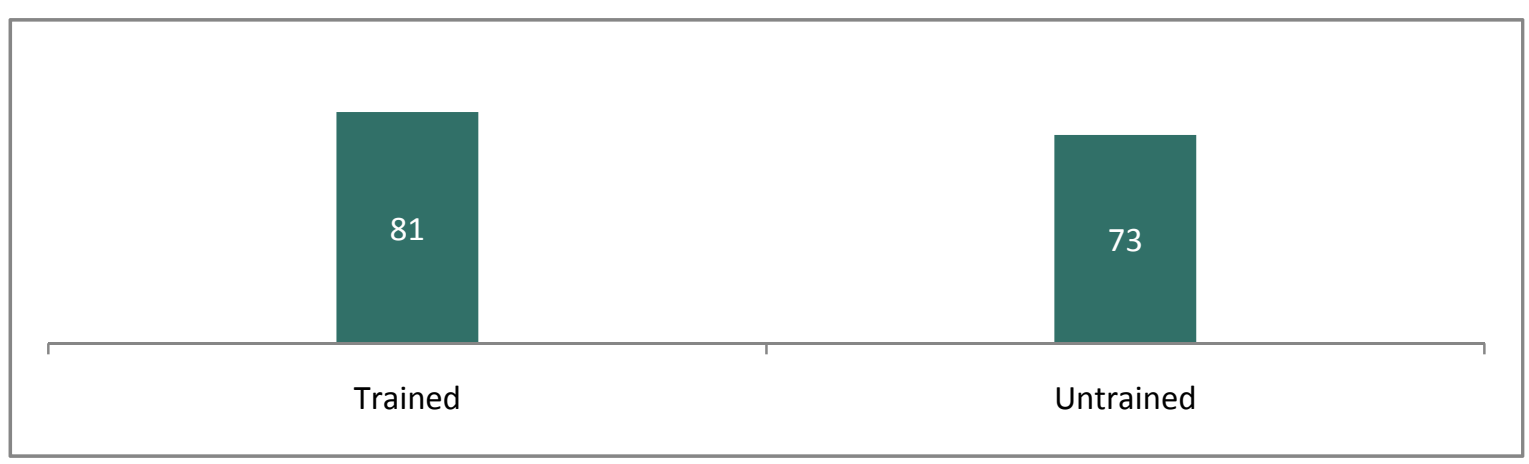


In cases which client/patient need cannot be addressed in the same facility, an important element for ensuring their satisfaction is proper referral, which includes accurate guidance about where to go, what to ask for, some indication of the procedure and cost involved. The study found few FP clients referred for services elsewhere-however, each documented referral was by a trained provider. The small number of referrals, however, could indicate that facilities were able to address most client need.

Clear instruction about follow-up visits is important for ensuring clients get the full benefit (effectiveness) of their treatment or method. More clients were told when to come for follow-up by trained providers than from untrained providers ( $89 \%$ versus $77 \%$ ). Those not instructed on follow-ups could potentially have been sterilization clients at higher-level facilities such as THQ and DHQ hospitals, therefore not requiring follow-up (Figure 4.15).

Figure 4.15: Percentage of clients instructed on follow up visits, by provider training status

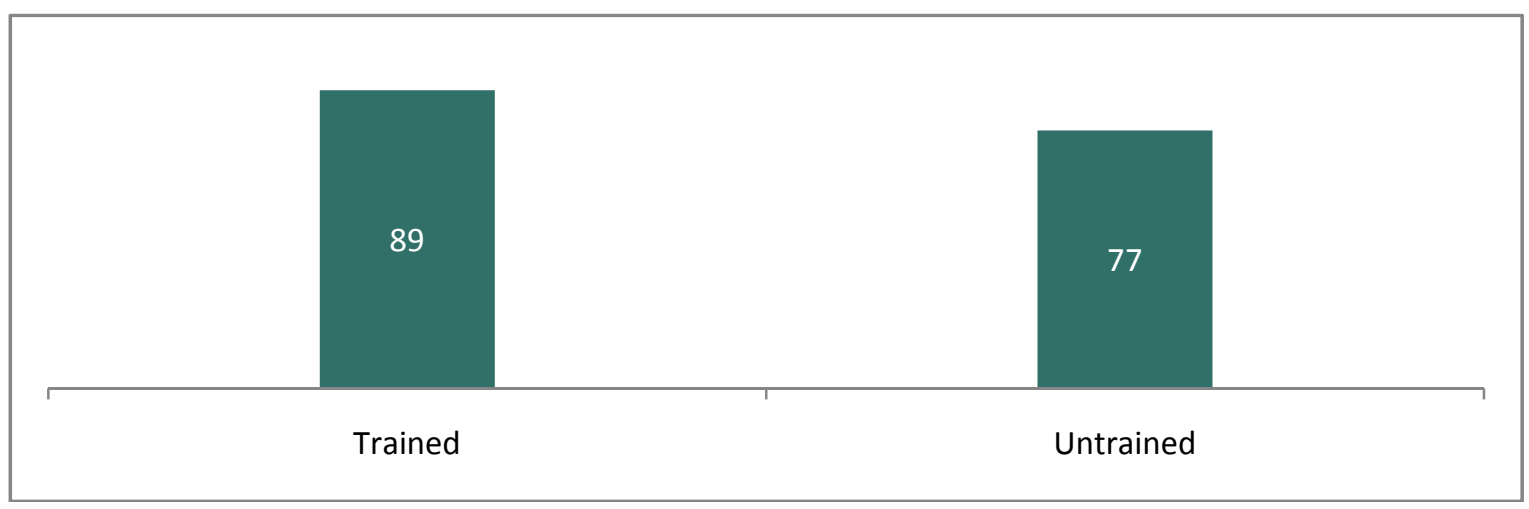

Identifying and assessing client service satisfaction is important in policy- and decision-making and can provide useful information for improving services.

Ninety-three percent of clients were satisfied with services provided and a further four percent were somewhat satisfied; only three percent showed dissatisfaction (Table 4.5). Moreover, 98 percent of clients said they would advise others to visit the same facility.

Table 4.5: Percentage of satisfied clients

\begin{tabular}{l|r} 
Satisfaction of clients & Percentage \\
Yes & 93.1 \\
\hline No & 3.0 \\
\hline Somewhat & 4.0 \\
\hline Advise someone to attend facility & 98.0 \\
\hline
\end{tabular}


Based on client-provider interactions and exit interviews, quality of care by providers trained in CCFPS is much better than untrained providers' care. The difference is apparent from the consultation start, when trained providers attempt to put a client at ease, ensuring confidentiality much more often than untrained providers. While both trained and untrained providers generally allow clients sufficient discussion and do not adopt dismissive attitudes, trained providers also identify clients' worries and fears, almost always providing information on different FP methods and possible side effects. Comparatively, almost half of untrained providers' clients did not receive FP method information, and only a quarter were provided information on side effects. Trained providers also generally employ a more holistic approach, assessing client social contexts and other health needs, and advise on follow-up visits more frequently than untrained providers.

The findings on quality of care are crucial and emphasize the need for offering CCFPS or SAHR trainings on a wider scale. With their more engaging attitude, trained providers will not only contribute to method continuation by existing clientele, but their holistic approach and advice on different FP choices will also attract new FP users. 



\section{Chapter 5: Conclusion}

This assessment, following FALAH's implementation, examined both public health facility readiness for providing $\mathrm{FP} /$ birth spacing services and quality of services. Facility readiness was evaluated by interviewing in-charges and providers, collecting data on infrastructure, services, staff availability, and contraceptive supplies. Service quality was measured through observing interactions between clients and providers, as well as exit interviews with clients at facilities. As the study primarily constitutes situation analysis as well as an evaluation of FALAH interventions, specifically training, the central part of the analysis is assessing the differences between trained and untrained facilities and staff. A facility is considered 'trained' when at least one staff member is FALAH-trained and, likewise, "trained staff" are those trained by FALAH. Visible and notable differences between trained and untrained staff have been discovered relating to service delivery.

Facility condition and readiness for service, including electrification, separate toilets for female clients or patients, waiting areas protected from sun or rain and cleanliness, have been found satisfactory, but uninterrupted electric supply is an issue at most facilities. Staffing is adequate. Counseling is important in FP/birth spacing service adoption, yet almost half of facilities have no separate room for counseling, which focuses primarily on $\mathrm{FP} /$ birth spacing with little attention to other aspects. IEC materials are prominently displayed by most facilities. Contraceptive availability is reasonably good and improved as a result of FALAH efforts, but stock outs are an issue. Specifically, lack of buffer stock is critical, for which FALAH made successful corrective efforts, and GoP agreed to provide three months' buffer stock to not only FALAH districts but all districts of Pakistan. Eighty-seven percent of facilities had at least one staff member trained in any one of the FALAH trainings. Regular contraceptive requisitioning was lacking, and as a result of FALAH's efforts, the situation improved, with 76 percent of facilities with trained providers now regularly requisitioning contraceptive supplies. For contraceptive supply sustainability, additional measures were suggested during field visits. For quality of services, the SAHR approach enhanced trained staff's skills. Overall, results are better in all aspects for trained staff compared to untrained staff.

FALAH's objective was to prepare public health facilities for better quality birth spacing/FP services, and thereby increase contraceptive prevalence. From evidence gathered in this assessment, it can be confidently stated that facilities and staff trained under FALAH are delivering better services. As a result, CPR increased in FALAH districts overall from 29.4 percent to 37.9 percent (Mahmood 2012). An independent analysis on contraceptive continuation rates in Pakistan also shows better continuation for users who were provided comprehensible information at method adoption (Saman and Mahmood 2012). SAHR training changed some important elements of provider attitude and behavior, but certainly more efforts are needed to sustain these changes and train other providers for dispensing quality services. 



\section{Annex-I}

Figure A1 SAHR, a systematic approach to meeting client's reproductive health needs

\begin{tabular}{|c|c|c|}
\hline \multirow{5}{*}{ Salutation $\rightarrow$} & \multicolumn{2}{|c|}{ TREAT THE CLIENT WITH RESPECT AND DIGNITY } \\
\hline & Welcome in a courteous and friendly manner & Ensure privacy and confidentiality \\
\hline & Show interest, empathy, and concern & Maintain atmosphere of equality \\
\hline & Show respect to the client and other family members & Call the client by his/her name \\
\hline & Create a tension-free and relaxed atmosphere & \\
\hline \multirow{14}{*}{ Assessment $\rightarrow$} & \multicolumn{2}{|c|}{ ASSESS THE CLIENT'S REPRODUCTIVE HEALTH NEEDS } \\
\hline & Observe the client & Assess client's reproductive health intentions \\
\hline & Listen carefully & If not pregnant, intent to have another child and when \\
\hline & Use communication tools like reflective listening & If pregnant, ask about intended place of delivery and \\
\hline & Provide ample time for consultation & delivery attendant \\
\hline & Identify the client's concerns, worries, and fears & Breastfeeding intentions \\
\hline & Assess the client's most pressing health need & Child immunization intentions \\
\hline & Assess other reproductive health needs (maternal health, child & Assess decisionmaking power in the household \\
\hline & health, family planning) & Explore preexisting knowledge of health issues/problems \\
\hline & Examine the client, if necessary & Determine underlying attitudes and health beliefs without \\
\hline & Ask permission to examine & becoming judgmental \\
\hline & Explain reasons for examination & \\
\hline & Inform client of findings, including causes and prognosis & \\
\hline & \multicolumn{2}{|c|}{ HELP NEGOTIATE A SOLUTION TO THE CLIENT'S REPRODUCTIVE HEALTH NEEDS } \\
\hline \multirow{13}{*}{ Help $\rightarrow$} & Address client's concerns and issues & Empower the client to address her/his needs \\
\hline & Provide information about options appropriate to her/his & Provide ample information about the negotiated solution \\
\hline & reproductive health needs & If the client has to be referred, provide him/her information about \\
\hline & Negotiate a mutually agreeable solution & Where to go \\
\hline & Maintain an atmosphere of equality & When to go \\
\hline & Provide ample time for listening to client's concerns & Distance involved \\
\hline & Encourage the client to speak & Convenient mode of transportation \\
\hline & Avoid blaming the client & Costs to be incurred \\
\hline & Maintain eye contact with client & Total time travel would take \\
\hline & Use appropriate tone and body language & Directions as how to reach the referred facility \\
\hline & Avoid aggressive and passive behavior & Involve family members, if present, in negotiated solution and \\
\hline & Be assertive & referral \\
\hline & \multicolumn{2}{|c|}{ REASSURE THE CLIENT AND RENEGOTIATE IF NECESSARY } \\
\hline \multirow{8}{*}{ Reassurance $\rightarrow$} & Ask the client to repeat instructions to ascertain understanding & Provide support and encouragement \\
\hline & $\begin{array}{l}\text { about } \\
\text { How to take medicine }\end{array}$ & $\begin{array}{l}\text { Reassure client that in case of need, he/she can contact the } \\
\text { provider }\end{array}$ \\
\hline & How to use contraceptives & Work with the client to overcome obstacles \\
\hline & How to follow other instructions & Renegotiate solution, if necessary \\
\hline & Allow client to ask questions & Community worker should also inform the client \\
\hline & Determine client's level of understanding & that provider will visit the client for follow-up \\
\hline & Explore client's ability to follow the negotiated solution & client can call provider, if necessary \\
\hline & Reassure and allay client's fears & client can visit provider directly \\
\hline
\end{tabular}

Source: Sathar Z, Jain A, RamaRao S, Haque MU and Kim J. Introducing Client-centered Reproductive Health Services in a Pakistani Setting. Studies in Family Planning 2005, 36:3; 221-234 


\section{Annex-II}
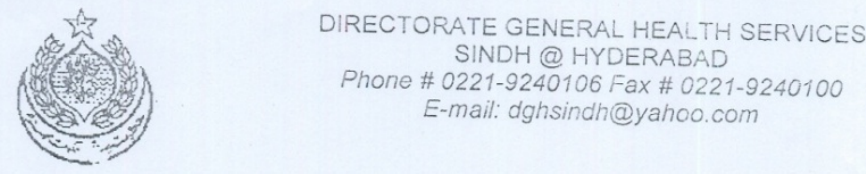

No. DGHSS/ - (St:)/- 833/840 / Dated: 05-10-2011

To

The Executive District Officer (Health)

Sukkur / Ghotki / Larkana / Sanghar / Thatta / Dadu.

Subject: $\quad$ Contraceptives Availability

Reference: Meeting held at this office with Chief of party ALFALAH along with his team, on $8^{\text {th }}$ September 2011.

Government of Pakistan is signatory to achieve MDGs at international forum which calls for lowering maternal and child mortality among others. Birth spacing and family planning is one way to achieve the health of mother and children among others. The ICPD Program of Action urges all countries to make reproductive Health Care and Family Planning Services accessible through Primary Health Care System to all individuals of appropriate ages not later than 2015 .

Keeping in view above, health facilities were decided to be involved in provision of contraceptives in the past and standard operating procedures (SOPS) for EDO (Health) were spelled out in the Manual of Contraceptive Logistics, Government of Pakistan , Ministry of Population Welfare Islamabad, 2007 (copy attached as ready reference). But it has been observed that the SOPs are not being implemented in letter and spirit resulting frequent stock outs at health facilities having manifold negative impact in honouring Government commitments at international fora.

The root cause in the way of contraceptives supplies is weak or absence of requisitioning system, therefore, the EDO should make sure a fully functional requisitioning system is in place and monthly report to be submitted to DG (Health)

EDOs (Health) should closely monitor the implementation through the following indicators:

- Current status of contraceptives at district and Facility leve

- How many Facilities have submitted their DOH-2 during last month

- How many Facilities have received contraceptives during last month .

- What measures have been taken for ensuring submission of $\mathrm{DOH}-2$ and receipt of contraceptives

For implementation of requisitioning system, directive/instructions should go from EDO (Health) with copy to DG(Health) to Facilities for sending DOH-2 Form on monthly basis and regularly. Reminders must go to who don't submit their DOH-2 and receive 
contraceptives with copy to DG (Health). For ensuring correctness of DOH-2 Forms, continuous vientation of LHVs or dealing providers is very much essential

Monthly meetings of the staff may be the useful Forum for the purpose where District store staff should do this job.

1. Strong distribution system for the delivery of contraceptives to Facilities be developed and reported to D.G office so that in the presence of contraceptives at district store no one facility is left out with out receipt of contraceptives. Supplies be made to Facilities each month at their door step instead of calling the staff for supplies.

2. Strict monitoring of Facilities be made by EDO (Health) and other concerned authorities and notices be served to such facilities who don't have contraceptives and have not made ..nmediate report to the concerned authorities. At least two visits be made by EDO (Health) each month.

3. In case of submission of CLR-6 to District Population Welfare Office/ Central Warehouse follow up be made and queries be satisfied if any. However, in case of non supply for more than one month, the report may be made to DG (Health) for taking up the matter with Central ware house at appropriate level.

4. As consumption of contraceptives for the previous quarter is the main hindrance in the way of supplies, the case of relaxation will be taken up with concerned authorities till fully functional requisitioning system. By the time the supplies be demanded on average base formula for district and Facilities with the demand of buffer stock. Copy of the CLR-6 be also sent to D. G office as well.

5. Don't wait for the stipulated time for submission of CLR-6 if stock out occurs at district store. Likewise instruction be issued to Facilities for immediate reporting to district if stock out occurs at facilities and all necessary measures be taken for immediate supplies to the such facilities apart from routine distribution.

6. Currently pending supplies from Central warehouse be reported immediately to take up the matter with Central Warehouse/other appropriate authorities.

7. Contraceptive supplies must be an essential agenda item in staff/DTC meetings to ensure contraceptive supplies at district and facilities.

8

Dr. (Capt.) Hafeez-ul-Haque Memon DIRECTOR GENERAL

HEALTH SERVICES SINDH @ HYDERABAD

- Copy submitted to Secretary Health, Health Department, Govt. of Sindh, Karachi.

- Copy to Zulfiqar Ali Sario, Provincial Coordinator FALAH, HANDS Head Office, Karachi.

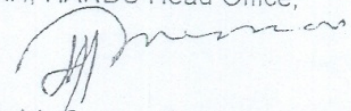

Dr. (Capt.) Hafeez-ul-Haque Memon DIRECTOR GENERAL 



\section{References}

Ali M, MA Bhatti and C Kuroiwa. 2008. Challenges in Access to and Utilization of Reproductive Health Care in Pakistan. Journal of Ayub Medical College Abbottabad 20(4).

Askew I, B Mensch and A Adewuyi. 1994. Indicators for Measuring the Quality of Family Planning Services in Nigeria. Studies in Family Planning 25 (5):268-283.

Bruce J. 1990. Fundamental Elements of Quality of Care: A Simple Framework. Studies in Family Planning 21(2): 61-91.

Cernada G, AKU Rob, SI Ameen and MS Ahmed. 1993. A Situation Analysis of Family Welfare Centre in Pakistan. Population Council Working Paper 4. Islamabad: The Population Council.

Creel LC, JV Sass and NV Yinger. 2002. Client-Centered Quality: Clients' Perspectives and Barriers to Receiving Care. The Population Council and Population Reference Bureau.

Creel LC, JV Sass and NV Yinger. 2002. Overview of Quality of Care in Reproductive Health: Definitions and Measurements of Quality. New Perspectives on Quality of Care 1. Washington, DC: Population Council and Population Reference Bureau.

Federal Bureau of Statistics, Pakistan. 2009. Pakistan Demographic Survey 2007. Islamabad.

Finance Division ,Pakistan Economic Survey,2010-2011,Government of Pakistan 2011, Islamabad, Pakistan.

Fapohunda B. 2012, Using Health Facility Assessment Data to Address Programmatic Questions: Illustrative Examples for Program managers, Measure Evaluation and USAID,

Government of Pakistan. 2007. Manual of Contraceptive Logistics. Ministry of Population Welfare, Monitoring \& Statistics Wing, Islamabad.

Jain A. 1989. Fertility Reduction and the Quality of Family Planning Services. Studies in Family Planning 20(1): 1-16.

Mahmood, A. 2012. Birth Spacing and Family Planning Uptake can Rise Rapidly in Pakistan: Evidence from FALAH: The Population Council.

Mensch B, A Fisher, I Askew and A Ajayi. 1994. Using Situation Analysis Data to Assess the Functioning of Family Planning Clinics in Nigeria, Tanzania and Zimbabwe. Studies in Family Planning 25(1): 18-31.

Miller K, R Miller, I Askew, MC Horn and L Ndhlovu. 1998. Clinic-based Family Planning and Reproductive Health Services in Africa: Findings from Situation Analysis Studies. New York: The Population Council.

Ministry of Population Welfare, 2010, Monthly Performance Report, Population Welfare Program, Government of Pakistan, Islamabad 
National Institute of Population Studies (NIPS), Islamabad, [Pakistan] and Macro International Inc. 2008. Pakistan Demographic and Health Survey 2006-07.

Naz, Saman, and Arshad Mahmood, 2012, Contraceptive use dynamics in Pakistan, Population Council, Islamabad

Population Council Islamabad, FALAH. Revised Edition 2009, Communication, Advocacy and Mobilization Strategy for Birth Spacing.

RamaRao, S. and R. Mohanam. 2003. The Quality of Family Planning Programs: Concepts, Measurements, Interventions, and Effects. Studies in family Planning, 34 (4):227-248.

RamaRao, S. and A. M. Mir. 2004. Transforming Relationships in Pakistani Villages. Quality/Calidad/Qualité No. 15.

Rudy, S., Tabbutt-Henry, J., Schaefer, L. and McQuide, P. Improving Client- Provider Interaction. Population Reports, Series Q, No. 1. Baltimore, Johns Hopkins Bloomberg School of Public Health, the INFO Project, Fall 2003

Sathar, Z,. Anrudh, J. Saumya, R, Minhaj, H. and Jacqueline,K. 2005. Introducing client-centered reproductive health services in a Pakistani setting. Studies in Family Planning, 2005 Sep; 36(3): 221-234

Sathar, Z., A. Mahmood and A. Faizzunisa. 2004. Women's health and poverty in Pakistan, proceedings of the fourth annual meeting of the Population Association of Pakistan, Faisalabad, Islamabad, Population Association of Pakistan

Sathar, Z \& Kazi, S., 1997, Women's Autonomy in the Context of Rural Pakistan, Pakistan Development Review, 39: 2 (Summer 2000) pp. 89-110, Institute for Development Economics, Islamabad

Shaikh BT and F. Rabbani. 2004. District health system-a challenge that still remains. Eastern Mediterranean Health Journal 10(1/2): 208-214.

World Bank. 2005. Pakistan Country Gender Assessment 2005: Bridging the Gender Gap Opportunities and Challenges. Washington, DC: World Bank.

WHO, DoH NWFP, UNICEF. 2010. An Assessment of Public Health Facilities in Kohat District NWFP: Draft Report. 